\title{
Blood Pressure Regulation by the Rostral Ventrolateral Medulla in Conscious Rats: Effects of Hypoxia, Hypercapnia, Baroreceptor Denervation, and Anesthesia
}

\author{
Ian C. Wenker, Chikara Abe, Kenneth E. Viar, Daniel S. Stornetta, ${ }^{\circledR R}$ uth L. Stornetta, and $₫$ Patrice G. Guyenet \\ Department of Pharmacology, University of Virginia, Charlottesville, Virginia 22908
}

\begin{abstract}
Current understanding of the contribution of $\mathrm{C} 1$ neurons to blood pressure (BP) regulation derives predominantly from experiments performed in anesthetized animals or reduced ex vivo preparations. Here, we use ArchaerhodopsinT3.0 (ArchT) loss-of-function optogenetics to explore BP regulation by $\mathrm{C} 1$ neurons in intact, unanesthetized rats. Using a lentivirus that expresses ArchT under the Phox2b-activated promoter PRSx8 (PRSx8-ArchT), $\sim 65 \%$ of transduced neurons were $\mathrm{C} 1$ (balance retrotrapezoid nucleus, RTN). Other rats received CaMKII-ArchT3.0 AAV2 (CaMKII-ArchT), which transduced $\mathrm{C} 1$ neurons and larger numbers of unidentified glutamatergic and GABAergic cells. Under anesthesia, ArchT photoactivation reduced sympathetic nerve activity and BP and silenced/strongly inhibited most (7/12) putative C1 neurons. In unanesthetized PRSx8-ArchT-treated rats breathing room air, bilateral ArchT photoactivation caused a very small BP reduction that was only slightly larger under hypercapnia $\left(6 \% \mathrm{FiCO}_{2}\right)$, but was greatly enhanced during hypoxia $\left(10\right.$ and $\left.12 \% \mathrm{FiO}_{2}\right)$, after sino-aortic denervation, or during isoflurane anesthesia. The degree of hypotension correlated with percentage of ArchT-transduced C1 neurons. ArchT photoactivation produced similar BP changes in CaMKII-ArchT-treated rats. Photoactivation in PRSX8-ArchT rats reduced breathing frequency $\left(F_{\mathrm{R}}\right)$, whereas $F_{\mathrm{R}}$ increased in CaMKII-ArchT rats. We conclude that the BP drop elicited by ArchT activation resulted from $\mathrm{C} 1$ neuron inhibition and was unrelated to breathing changes. $\mathrm{C} 1$ neurons have low activity under normoxia, but their activation is important to BP stability during hypoxia or anesthesia and contributes greatly to the hypertension caused by baroreceptor deafferentation. Finally, $\mathrm{C} 1$ neurons are marginally activated by hypercapnia and the large breathing stimulation caused by this stimulus has very little impact on resting BP.
\end{abstract}

Key words: baroreceptor; blood pressure; chemoreflex; optogenetics; RVLM; sympathetic

Significance Statement

$\mathrm{C} 1$ neurons are glutamatergic/peptidergic/catecholaminergic neurons located in the medulla oblongata, which may operate as a switchboard for differential, behavior-appropriate activation of selected sympathetic efferents. Based largely on experimentation in anesthetized or reduced preparations, a rostrally located subset of $\mathrm{Cl}$ neurons may contribute to both BP stabilization and dysregulation (hypertension). Here, we used Archaerhodopsin-based loss-of-function optogenetics to explore the contribution of these neurons to $\mathrm{BP}$ in conscious rats. The results suggest that $\mathrm{C} 1$ neurons contribute little to resting $\mathrm{BP}$ under normoxia or hypercapnia, $\mathrm{C} 1$ neuron discharge is restrained continuously by arterial baroreceptors, and $\mathrm{C} 1$ neuron activation is critical to stabilize $\mathrm{BP}$ under hypoxia or anesthesia. This optogenetic approach could also be useful to explore the role of $\mathrm{C} 1$ neurons during specific behaviors or in hypertensive models.

\section{Introduction}

In anesthetized or reduced preparations, the rostral ventrolateral medulla (RVLM) is a critical node for blood pressure (BP) con-

Received Dec. 22, 2016; revised March 23, 2017; accepted March 26, 2017.

Author contributions: I.C.W., R.L.S., and P.G.G. designed research; I.C.W., C.A., K.E.V., D.S.S., and R.L.S. performed research; I.C.W. and R.L.S. analyzed data; I.C.W., R.L.S., and P.G.G. wrote the paper.

This work was supported by the National Institutes of Health (Grants R01 HL074011 and R01 HL 028785 to P.G.G. and Grant F32HL127975 to I.C.W.).

The authors declare no competing financial interests.

C. Abe's present address: Department of Physiology, Gifu University Graduate School of Medicine, Gifu, Japan. trol (Guyenet, 2006; Marina et al., 2011; Schreihofer and Sved, 2011). BP rises/decreases when RVLM neurons are bulk activated/inhibited with amino acids or GABA-mimetic compounds; increases or decreases in BP can also be produced by targeting RVLM neurons with appropriate optogenetic or pharmacoge-

Correspondence should be addressed to Patrice G. Guyenet, Ph.D., University of Virginia Health System Pinn Hall, Room 5240, 1340 Jefferson Park Avenue, P.0. Box 800735, Charlottesville, VA 22908-0735. E-mail: pgg@virginia.edu.

DOI:10.1523/JNEUROSCI.3922-16.2017

Copyright $\odot 2017$ the authors $\quad 0270-6474 / 17 / 374565-19 \$ 15.00 / 0$ 
netic actuators (Guyenet, 2006; Kanbar et al., 2010; Marina et al., 2011; Schreihofer and Sved, 2011; Geraldes et al., 2014). The BP changes result primarily from variations in sympathetic nerve activity (SNA) and are presumably mediated via monosynaptic projections from RVLM to sympathetic preganglionic neurons (Ross et al., 1984; Brown and Guyenet, 1985). These "presympathetic" neurons are glutamatergic, with a large subset (the $\mathrm{C} 1$ neurons) also being catecholaminergic; their discharge increases when $\mathrm{BP}$ or arterial $\mathrm{PO}_{2}$ drops and often covaries with that of selected sympathetic efferents (Sun and Reis, 1993; McAllen et al., 1995; Guyenet, 2006; Stornetta, 2009).

The extent to which the RVLM contributes to BP regulation in intact conscious mammals and the importance of the monosynaptic input to sympathetic preganglionic neurons are yet to be determined. RVLM presympathetic neurons have multiple brain targets in addition to sympathetic preganglionic neurons, the relative contribution of the $\mathrm{C} 1$ and other presympathetic neurons is unclear, and the local circuitry within RVLM is unexplored. Sympathetic preganglionic neurons receive input from many CNS regions in addition to the RVLM. Most of these inputs, notably the numerous spinal interneurons, do not contribute to BP under anesthesia or in reduced preparations (Jansen et al., 1995a; Jansen et al., 1995b; Krupp et al., 1997). In conscious rats, optogenetic activation of the $\mathrm{C} 1$ neurons increases $\mathrm{BP}$, activates breathing, and produces arousal, but these results do not clarify the physiological circumstances under which these neurons are recruited (Kanbar et al., 2010; Burke et al., 2014). This question has been addressed to some degree by examining the deficits caused by lesions of the $\mathrm{C} 1$ neurons with a saporin-based toxin (Schreihofer et al., 2000). In conscious rats, such lesions reduce resting $\mathrm{BP}$ only minimally, but they attenuate the homeostatic responses to hypotension or glucoprivation (Madden et al., 2006). These results suggest that $C 1$ neurons are less important to resting $\mathrm{BP}$ in conscious animals than in anesthetized or reduced preparations; however, they also suggest that $\mathrm{C} 1$ neurons are activated during hypotension or hypoglycemia or, at least, facilitate countervailing responses. The disadvantages of saporin-based lesions are their irreversibility and the incomplete selectivity of the toxin (e.g., damaged astrocytes and A5 catecholaminergic neurons; Madden et al., 2006; Lin et al., 2013).

To measure the moment-to-moment contribution of RVLM to $\mathrm{BP}$ in intact unanesthetized rats, we used loss-of-function optogenetics (Chow et al., 2010). RVLM neurons were transduced bilaterally to express the photoactivatable proton pump Archaerhodopsin (ArchT) (Han et al., 2011) and we measured the cardiorespiratory changes [BP, heart rate (HR), breathing parameters] elicited by brief bilateral inhibition of the ArchT-expressing neurons. This approach allowed us to test the contribution to BP of the same subset of RVLM neurons under multiple experimental conditions within a few hours or over weeks.

Using this technology, we asked the following questions. What is the contribution of RVLM neurons and, in particular, of $\mathrm{C} 1$ neurons, to resting $\mathrm{BP}$ in quietly resting rats? Is it increased or decreased by general anesthesia? Does the RVLM stabilize BP under hypoxia? Does hypercapnia increase BP by activating the C1 neurons? Finally, how does the RVLM regulate BP shortly after surgical removal of the arterial baroreceptors and up to 3 weeks thereafter, when BP has returned to control?

\section{Materials and Methods}

Animals. We used male Sprague Dawley rats $(n=28 ; 400-550$ g; Taconic). All procedures conformed to the National Institutes of Health's Guide for the Care and Use of Laboratory Animals and were approved by the University of Virginia Animal Care and Use Committee. Animals were housed under a standard $12 \mathrm{~h}$ light/dark cycle with ad libitum access to food and water.

Viral vectors. In this study, we used two vectors to transduce RVLM neurons with the third-generation photoactivatable proton pump ArchaerhodopsinT3.0 fused to eYFP (ArchT-eYFP) (Han et al., 2011; Mattis et al., 2011; Burke et al., 2015): (1) a lentiviral vector that expresses the transgene under the control of the Phox $2 \mathrm{~b}$-responsive artificial promoter PRSx8 (Hwang et al., 2001) and (2) an adeno-associated vector (AAV2) that expresses ArchT-eYFP under the control of the $\mathrm{Ca}^{2+} /$ calmodulindependent protein kinase II (CaMKII) promoter (Watakabe et al., 2015). When injected into the RVLM, the PRSx8 lentiviral vector transduces almost exclusively Phox $2 \mathrm{~b}$-expressing neurons, which consist of $\mathrm{C} 1$ catecholaminergic (C1 neurons) and retrotrapezoid nucleus (RTN) neurons (Abbott et al., 2009a). RTN mediates the effects of $\mathrm{CO}_{2}$ on breathing and has little effect on BP. In the cortex, AAV-CaMKII transduces excitatory neurons preferentially, with some labeling of inhibitory neurons (Watakabe et al., 2015). The neuronal selectivity of this vector in the RVLM has not been described previously. These vectors, henceforth called PRSx8-ArchT and CaMKII-ArchT, were produced by the University of North Carolina vector core. CaMKII-ArchT was used without dilution $\left(\sim 3.0 \times 10^{12}\right.$ viral particles/ml). PRSx8-ArchT was diluted to a final titer of $\sim 3.0 \times 10^{8}$ viral particles $/ \mathrm{ml}$ with sterile PBS. The physiological experiments were conducted 6-8 weeks after injection of PRSx8ArchT and 2-3 weeks after CaMKII-ArchT vector when maximum and stable physiological effects were induced by laser light.

Stereotaxic injection of viral vectors into the RVLM. The vectors were pressure injected into RVLM via glass pipettes that were placed in the RVLM using electrophysiological cues as described previously (Basting et al., 2015). Briefly, rats were anesthetized with a mixture of ketamine (75 $\left.\mathrm{mg} \mathrm{kg}^{-1}\right)$, xylazine $\left(5 \mathrm{mg} \mathrm{kg}^{-1}\right)$, and acepromazine $\left(1 \mathrm{mg} \mathrm{kg}^{-1}\right)$ given intraperitoneally, which eliminated the corneal reflex and hindpaw withdrawal to a strong pinch. Additional anesthetic was administered as necessary during surgery ( $25 \%$ of the original dose, intraperitoneally or intramuscular). Body temperature was kept close to $37^{\circ} \mathrm{C}$ with a servocontrolled heating pad and a blanket. All surgical procedures were performed under standard aseptic conditions. Postoperatively, all rats received ampicillin $\left(125 \mathrm{mg} \mathrm{kg}^{-1}\right.$, i.p.) and ketoprofen $\left(3-5 \mathrm{mg} \mathrm{kg}^{-1}\right.$, s.c.) for 2 consecutive days. An incision over the mandible was made to expose the facial nerve for antidromic activation of facial motor neurons. The rat was then placed prone on a stereotaxic apparatus (bite bar set at $-3.5 \mathrm{~mm}$ for flat skull; David Kopf Instruments). Holes ( $\sim 2 \mathrm{~mm}$ diameter) were drilled bilaterally into the occipital plate caudal to the parietooccipital suture. The viral vectors were loaded into a $1.2 \mathrm{~mm}$ internal diameter glass pipette broken to a $25 \mu \mathrm{m}$ tip (external diameter). The caudal and ventral poles of the facial motor nucleus were identified in each rat by mapping antidromic-evoked potentials elicited by stimulating the facial nerve (Brown and Guyenet, 1985). In most cases, viral vectors were delivered bilaterally by making six injections on each side (100-120 nl/injection) starting just caudal to the end of the facial motor nucleus, with five subsequent injections occurring every $100 \mu \mathrm{m}$ caudally. The tip of the optical fiber was placed $0.4 \mathrm{~mm}$ above the geometric center of the 6 injection sites, typically $\sim 0.25 \mathrm{~mm}$ caudal to the facial motor nucleus. The fibers were affixed to the skull using Loctite 3092. For the unit recording experiments described below, viral vectors were injected unilaterally and optical fibers were not implanted.

Implantation of telemetric BP probes. Five to $7 \mathrm{~d}$ before physiological experiments, rats were anesthetized with isoflurane (1.5-3\%). Isoflurane levels were adjusted as needed to ensure appropriate depth of anesthesia throughout the procedure. Using aseptic technique, radiotelemetry probes (PA-C10; Datasciences International) were inserted into the descending aorta via the right femoral artery. Rats were given postoperative ampicillin ( $125 \mathrm{mg} \mathrm{kg}^{-1}$, i.p.), and ketoprofen $(3-5 \mathrm{mg}$ $\mathrm{kg}^{-1}$, s.c.) for 2 consecutive days and allowed at least $5 \mathrm{~d}$ for recovery before experimentation.

Sinoaortic denervation (SAD). SAD was performed using aseptic technique as described previously (Krieger, 1964; Abe et al., 2013). Rats were anesthetized with isoflurane (1.5-3\%). First, the aortic depressor nerve was isolated and transected on both sides through a midcervical incision. 
Then, the carotid sinuses were isolated from the surrounding connective tissue and $10 \%$ phenol in ethanol was applied to complete the denervation. Sham-operated rats were subjected to the entire surgical procedure except that the aortic depressor nerves, the carotid sinus nerves, and the sinus region were left untouched. All rats were given postoperative ampicillin (125 $\mathrm{mg} \mathrm{kg}^{-1}$, i.p.) and ketoprofen $\left(3-5 \mathrm{mg} \mathrm{kg}^{-1}\right.$, s.c.) for 2 consecutive days.

Single-unit and sympathetic nerve recordings in anesthetized rats. Six to 8 weeks after injection of PRSx8-ArchT or 2 to 3 weeks after injection of CaMKII-ArchT into the left RVLM, rats were anesthetized with isoflurane $(1.5-3 \%)$ and mechanically ventilated via a tracheostomy $(100 \%$ $\mathrm{O}_{2}$ ). A catheter was inserted into the femoral artery to record BP and a femoral vein was cannulated for drug administration. At this point, anesthesia was switched to urethane $/ \alpha$-chloralose $(500$ and $50 \mathrm{mg} / \mathrm{ml}$, respectively; initial dose: $2 \mathrm{ml} / \mathrm{kg}$ ). This mixture was administered intravenously over $20 \mathrm{~min}$ while tapering the isoflurane concentration to 0 . During this switch and for the rest of the experiment, anesthetic depth was maintained at a level that eliminated the withdrawal reflex to a strong paw pinch. Body temperature was kept close to $37^{\circ} \mathrm{C}$ with a servocontrolled heating pad and a blanket. End-expiratory $\mathrm{CO}_{2}$ was monitored continuously with a micro-capnometer (Columbus Instruments) and maintained between $3.5 \%$ and $5.0 \%$.

For single-unit recording, rats were placed prone on a stereotaxic apparatus (bite bar set at $-3.5 \mathrm{~mm}$ for flat skull; David Kopf Instruments). A 3-4 $\mathrm{mm}$ window was drilled into the occipital plate caudal to the parieto-occipital suture through which a recording pipette filled with $2 \mathrm{M}$ $\mathrm{NaCl}(3-7 \mathrm{M} \Omega$ ) and a $200 \mu \mathrm{m}$ optical fiber was inserted into the brain. The recording pipette was first used to map the coordinates of the facial motor nucleus, as described above, and then moved caudally to record neurons located in the RVLM $(0-800 \mu \mathrm{m}$ caudal to this nucleus; depth within $250 \mu \mathrm{m}$ of the bottom of the facial motor nucleus). Single action potentials were amplified tenfold (Axoclamp 2B; Molecular Devices, DC-8 KHz) in bridge mode, further amplified, band-pass filtered using an AC amplifier $(1000 \times ; 400 \mathrm{~Hz}$ and $8 \mathrm{kHz})$, and then digitized. A $200-\mu \mathrm{m}$-diameter optical fiber coupled to a green laser (532 nm; Shanghai Laser and Optics Century) was inserted into the brain at a $15^{\circ}$ angle and the tip placed $\sim 0.3 \mathrm{~mm}$ dorsal from the lower edge of the facial motor nucleus and $\sim 0.2 \mathrm{~mm}$ caudal from the caudal edge of this nucleus. RVLM-barosensitive unit recordings were identified as described previously (Haselton and Guyenet, 1989b). To test their response to ArchT photoactivation, green laser light $(532 \mathrm{~nm}, 10 \mathrm{~mW})$ was applied continuously for 5-20 s.

SNA was recorded in six rats anesthetized with urethane $/ \alpha$-chloralose as described above. These rats had bilateral preimplanted optical fibers targeting ArchT-transduced RVLM neurons and had responded strongly to light in the conscious state. An incision was made lateral to the vertebral column, allowing for retroperitoneal access to the body cavity. A postganglionic section of the splanchnic sympathetic nerve was isolated and placed over two stainless steel wires (AS633; Cooner Wires). The nerve and electrodes were then buried in Kwik-Sil (World Precision Instruments). Multiunit activity was amplified (1000×), band-pass filtered (100-3000 Hz; CWE), and digitized. The background noise was determined as the voltage remaining at saturation of the baroreflex as determined by injecting a large dose of phenylephrine (5-10 $\mu \mathrm{g} / \mathrm{kg})$. To test the SNA response to ArchT photoactivation, green light $(532 \mathrm{~nm}$; Shanghai Laser and Optics Century) was applied continuously in 5-20 s episodes.

Physiological experiments in freely behaving rats. Six to 8 weeks after bilateral injection of PRSx8-ArchT or 2-3 weeks after bilateral injection of CaMKII-ArchT, rats were tested in a plethysmography chamber (EMKA Technologies) custom modified to allow bilateral tethered optical stimulation of the RVLM. Before the actual experiments, rats were repeatedly habituated to these surroundings, which were isolated visually and had low ambient noise. On the day of the experiment, rats were lightly anesthetized with isoflurane (induction with $5 \%$, maintenance with $2 \%$ in $100 \%$ oxygen for $<1 \mathrm{~min}$ ) to permit cleaning and connection of the ferrules. A $200-\mu \mathrm{m}$-thick multimode optical fiber terminated with a ferrule was mated to the implanted ferrule with a zirconia sleeve. Optical matching gel (Fiber Instrument Sales) was applied at the ferrule junction to reduce light loss. A minimum of $1 \mathrm{~h}$ was allowed for recovery from anesthesia and the emergence of stable breathing and BP. Recordings were made between 10:00 A.M. and 6:00 P.M. The ventilatory response to RVLM neuronal inhibition was assessed using barometric, unrestrained whole-body plethysmography (EMKA Technologies). The signal generated by the differential pressure transducer connected to the plethysmography chamber was amplified, band-pass filtered between 0.1 and $20 \mathrm{~Hz}$, and being digitized. The plethysmography chamber was flushed continuously with $1.5 \mathrm{~L} / \mathrm{min}$ of $21 \% \mathrm{O}_{2}$ balanced with $\mathrm{N}_{2}$ regulated by computer-driven mass flow controllers for $\mathrm{O}_{2}, \mathrm{~N}_{2}$, and $\mathrm{CO}_{2}$ (Alicat). Temperature and humidity within the plethysmography chamber were kept stable within experiments $\left( \pm 0.5^{\circ} \mathrm{C}, \pm 5 \%\right.$ relative humidity) and between experiments $\left(23-25^{\circ} \mathrm{C}\right.$ ambient room temperature, $40-60 \%$ relative humidity). On the day of experimentation, BP probes were activated by a magnet and signals were obtained from a radio receiver connected to a bridge amplifier (Data Science International). Calibration of plethysmography system and BP probes were done before experimentation as per manufacturer specifications. Photoinhibition of ArchT-expressing neurons was achieved with a green laser $(532 \mathrm{~nm}$; Shanghai Laser and Optics Century). Green light was applied bilaterally using a splitter through $200-\mu \mathrm{m}$-thick multimode optical fiber (Thorlabs) in $10 \mathrm{~s}$ episodes of continuous illumination with $\sim 5 \mathrm{~mW}$ of light output at the tip of the implanted fibers. The transmission efficiency of each implantable optical fiber was tested before implantation with a light meter (Thorlabs).

Analysis of physiological data. All analog signals (single units, multifiber nerve activity, plethysmography, and BP, both telemetric and via catheter) were digitized with an A-D interface (Micro1401; Cambridge Electronic Design) and recorded on a desktop computer using Spike2 software (Cambridge Electronic Design). Unit and nerve recording were sampled at $10 \mathrm{kHz}$, plethysmography at $100 \mathrm{~Hz}$, and $\mathrm{BP}$ at $300 \mathrm{~Hz}$.

A minimum of two photoinhibition trials were conducted per individual unit recording of a barosensitive RVLM neuron and a minimum of four photoinhibition trials for each condition [control and sodium nitroprusside (SNP)] during nerve recording. Single-unit frequency was measured by creating a threshold event channel in the Spike2 software. Action potential frequency was measured during the $10 \mathrm{~s}$ preceding and during laser light inhibition. Nerve activity was rectified and integrated and the amplitude was measured during the $10 \mathrm{~s}$ preceding and during laser light inhibition in each condition (control and SNP).

For conscious physiological experiments, a minimum of five photoinhibition trials were conducted in each rat at each level of $\mathrm{FiO}_{2}$ or $\mathrm{FiCO}_{2}$. Baseline cardiorespiratory variables [breathing frequency $\left(F_{\mathrm{R}}\right)$, tidal volume $\left(V_{\mathrm{T}}\right), \mathrm{BP}$, and $\mathrm{HR}$ ] were measured during the $10 \mathrm{~s}$ preceding light delivery. The effect of the light on $F_{\mathrm{R}}, V_{\mathrm{T}}$, and HR were assessed by measuring the average value of these parameters during the entire light pulse (10 s). BP responses to changes in SNA are low-pass filtered by the properties of vascular smooth muscles and can be delayed by several seconds. For this reason, we assessed the full effect of the neural inhibition by measuring the light-induced BP nadir averaged over $2 \mathrm{~s}$, as opposed to the full $10 \mathrm{~s}$ of photoinhibition. $F_{\mathrm{R}}$ (breaths/minute) and $V_{\mathrm{T}}$ (area under the curve during the inspiratory period calibrated to waveforms generated by injecting $5 \mathrm{ml}$ of dry air from a syringe during the experiment, expressed in milliliters per $1 \mathrm{~kg}$ body weight) were calculated using Spike software version 7.3 (Cambridge Electronics). These values were used to calculate minute ventilation $\left(V_{\mathrm{E}}=F_{\mathrm{R}} \times V_{\mathrm{T}}\right.$, expressed in milliliters per $1 \mathrm{~kg}$ body weight per minute).

$\mathrm{BP}$ variability was measured during a $30 \mathrm{~min}$ period selected after the animal had acclimated to the chamber. MAP was collected in $5 \mathrm{~s}$ bins (360 data points). These values were plotted as a frequency histogram. The SD of each dataset was calculated.

Spontaneous baroreflex sensitivity (sBRS) was analyzed by the "sequence method" (Oosting et al., 1997; Bajić et al., 2010). Systolic BP (SBP) and pulse interval (PI) were derived from 10 to 15 min segments of arterial BP data for each condition (control, hypoxia and hypercapnia). SBP and PI series underwent smoothing before identifying sequences of four or more consecutive increases or decreases in SBP. These SBP values were plotted against corresponding PI values at 3, 4, and 5 beat delays. 
The mean slope (expressed in $\mathrm{ms} / \mathrm{mmHg}$ ) and $R^{2}$ for the three lines were calculated for each sequence. For a sequence to be used in estimating the sBRS, it had to meet four criteria; (1) four or more beats with (2) a minimum change in SBP of $1 \mathrm{mmHg}$, (3) a positive slope, and (4) $R^{2}>$ 0.8 . This process identified numerous sequences and reported the sBRS as the average slope of the regression line in $\mathrm{ms} / \mathrm{mmHg}$ for each condition for each rat (examples in Fig. 13B).

Histology. As described previously (Abbott et al., 2012), rats were anesthetized and perfused transcardially with $4 \%$ paraformaldehyde. Brains and spinal cords were removed and postfixed in the same fixative for $16-18 \mathrm{~h}$ at $4^{\circ} \mathrm{C}$. Brains and spinal cords were sectioned and placed in cryoprotectant (30\% ethylene glycol, 20\% glycerol, 50\% $100 \mathrm{~mm}$ sodium phosphate buffer, $\mathrm{pH} 7.4$ ) at $-20^{\circ} \mathrm{C}$ until further processing. For brainstem sections, ArchT-eYFP and tyrosine-hydroxylase (TH) were identified by immunohistochemistry, and spinal cord sections were processed for ArchT-eYFP immunoreactivity (chicken anti-GFP, 1:1000, Aves Laboratories, and sheep anti-TH, 1:2000, Millipore).

For in situ hybridization, we used the RNAscope Multiplex Fluorescent Assay kit (Advanced Cell Diagnostics). Briefly, sections were washed in sterile PBS, mounted on charged slides, and dried overnight. All sections for an experimental "run" were mounted and reacted on the same slide and thus experienced the same experimental conditions and solutions. After two rinses in sterile water, sections were incubated with "protease 4 " for $30 \mathrm{~min}$ at $42^{\circ} \mathrm{C}$. Sections were rinsed twice in sterile water and incubated in RNAscope catalog oligonucleotide probes for GAD1 (glutamic acid decarboxylase-1) and VGlut2 (vesicular glutamate transporter 2, Slc17a6) mRNA transcripts for $2 \mathrm{~h}$ at $40^{\circ} \mathrm{C}$. GAD1 probes consisted of 20 oligo pairs directed to the region between 950 and $1872 \mathrm{bp}$ of the GAD1 rat sequence (accession number NM_017007.1). VGlut2 probes consisted of $20 \mathrm{bp}$ directed to the region between 1109 and 2024 bp of the VGlut2 rat sequence (accession number NM_053427.1). After incubation in probes, tissue was treated exactly according to the manufacturer's protocol (ACD) using Amp 4B-FL, resulting in GAD1 transcripts labeled with Atto 647 and VGlut2 transcripts labeled with Atto 550. After the last step of the RNAscope protocol, slides were rinsed in $100 \mathrm{~mm}$ TBS and incubated for $10 \mathrm{~min}$ in blocking solution (10\% horse serum with $0.1 \%$ Triton in TBS), followed by $1 \mathrm{~h}$ incubation in primary antibody against GFP (chicken anti-GFP from Aves Laboratories at 1:1000 in blocking solution). Slides were then rinsed in TBS and incubated for $30 \mathrm{~min}$ in Alexa Fluor 488 anti-chicken secondary antibody (1:500; Jackson ImmunoResearch) and rinsed in TBS. After brief air drying, slides were covered with Prolong Gold Antifade mountant (Invitrogen).

Cell mapping, counting, and photography were done using the Neurolucida system (MBF Bioscience) with a Zeiss Axioskop microscope with computer-driven stage and Zeiss MRc camera. Except when specified, cell counts were obtained from a one in six series of $30 \mu \mathrm{m}$ transverse sections encompassing the RVLM and immediately adjacent region.

Statistics. Prism software version 7 (GraphPad) was used. Only datasets that passed normality with D'Agostino and Pearson (groups of 8 or more) and Shapiro-Wilk (groups $<8$ ) tests were further analyzed for differences within and between groups using one-way or two-way ANOVA, followed by a multiple-comparisons test. Unless specified otherwise, F statistics reported for the two-way ANOVAs are the interaction effects. If data were not normally distributed, Friedman's or KruskalWallis tests were conducted, as appropriate, with Dunn's post hoc multiple comparisons. Linear regression analysis was used to examine the relationship between the percentage of transduced $\mathrm{C} 1$ and RTN neurons versus the change in MAP during isoflurane. All values are expressed as means \pm SE.

\section{Results}

Except where indicated, all results were obtained using the same rats (seven animals injected with PRSx8-ArchT lentiviral vector and eight or nine animals injected with CaMKII-ArchT AAV2). These rats (henceforth referred to as high-responders) were se- lected because they exhibited the largest hypotensive responses during ArchT activation under isoflurane anesthesia or hypoxia.

\section{Histology}

The following section focuses on the high-responders; seven PRSx8-ArchT and seven CaMKII-ArchT rats (two of the highresponding CaMKII-ArchT animals were not successfully processed histologically). ArchT was identified by detecting eYFP immunoreactivity (Fig. 1 $A, B$ ). The transduced neurons were confined to the RVLM and its rostral extension under the caudal end of the facial motor nucleus.

In the PRSx8-ArchT cohort (Fig. 1C), $53 \pm 4 \%$ of the $\mathrm{C} 1$ neurons located $0-500 \mu \mathrm{m}$ caudal to the facial motor nucleus were transduced (range: $37-65 \% ; n=7$ ). Approximately twothirds of the eYFP-immunoreactive (ir) neurons were TH-ir (Fig. $1 A, C$ ) and, within the RVLM proper (caudal to the facial motor nucleus, i.e., bregma $-11.6 \mathrm{~mm}$ ), $64 \pm 8 \%$ of transduced neurons were $\mathrm{C} 1$ cells $\left(\mathrm{TH}^{+}\right) . \mathrm{TH}^{-}$transduced neurons were mostly located under the caudal half of the facial motor nucleus within the retrotrapezoid nucleus (RTN), a group of $\mathrm{CO}_{2}$-responsive glutamatergic neurons that mediate the central respiratory chemoreflex (Abbott et al., 2009b).

In the CaMKII-ArchT cohort, transduced neurons were also confined to the RVLM and this population also included $\mathrm{TH}$-ir neurons (Fig. 1B). However, a smaller proportion of the TH-ir neurons were transduced in these rats $(23 \pm 5 \%$; range $12-27 \%$; $n=7$ ) and the vast majority of ArchT-expressing neurons were not catecholaminergic (Fig. 1D). ArchT-eYFP axonal projections to the thoracic spinal cord targeted preferentially the intermediolateral cell column, thereby showing that RVLM "presympathetic" neurons (probably $\mathrm{C} 1$, but possibly other types as well) were transduced (Fig. 1E). Few $\mathrm{TH}^{-}$neurons were located within the RTN region in the CaMKII-ArchT group. The majority of ArchT-transduced neurons were located caudal to the facial motor nucleus (Fig. 1D). In addition to bulbospinal C1 neurons, this region harbors non-catecholaminergic glutamatergic $\left(\right.$ VGlut ${ }^{+}$) neurons of undetermined function and the "Bötzinger" subdivision of the respiratory column, which consists mostly of inhibitory neurons (Smith et al., 2007). To determine the phenotype of neurons transduced with the CaMKII-ArchT vector, we investigated whether ArchT (eYFP immunoreactivity) colocalized with VGlut2 or GAD1 transcripts. The ratio of VGlut2 to GAD1 ArchT-transduced neurons near the site of injection was $\sim 2$ to 1 (61.4\% VGlut2, 30.7\% GAD1, and 0.8\% VGlut2/GAD1; $n=3$ rats) and very few cells contained neither marker (7.1\%).

In short, both vectors resulted in expression of ArchT confined to the RVLM. PRSx8-ArchT transduced mainly C1 neurons and lesser numbers of RTN neurons. CaMKII-ArchT transduced a wide variety of excitatory or inhibitory neurons that included bulbospinal $\mathrm{C} 1$ and possibly other BP-regulating neurons.

\section{ArchT photoactivation silences RVLM-barosensitive units and reduces sympathetic nerve activity in anesthetized rats} We examined the response of 100 randomly encountered active RVLM neurons to $532 \mathrm{~nm}$ light in chloralose-urethane-anesthetized rats that had received unilateral injections of vector. Fifty-two units were recorded from rats injected with PRSx8-ArchT $(n=3)$ and the rest recorded from rats injected with CaMKII-ArchT $(n=2)$. All recordings were made $0-500 \mu \mathrm{m}$ caudal to the facial motor nucleus.

Twelve neurons were identified as barosensitive (silenced when $\mathrm{BP}$ was raised $20-40 \mathrm{mmHg}$ above resting level; Fig. $2 \mathrm{~A}, \mathrm{~B}$ ). Within the sampled region, virtually all such barosensitive neurons are bulbospinal and the majority $(\sim 70 \%)$ are $\mathrm{Cl}$ cells 

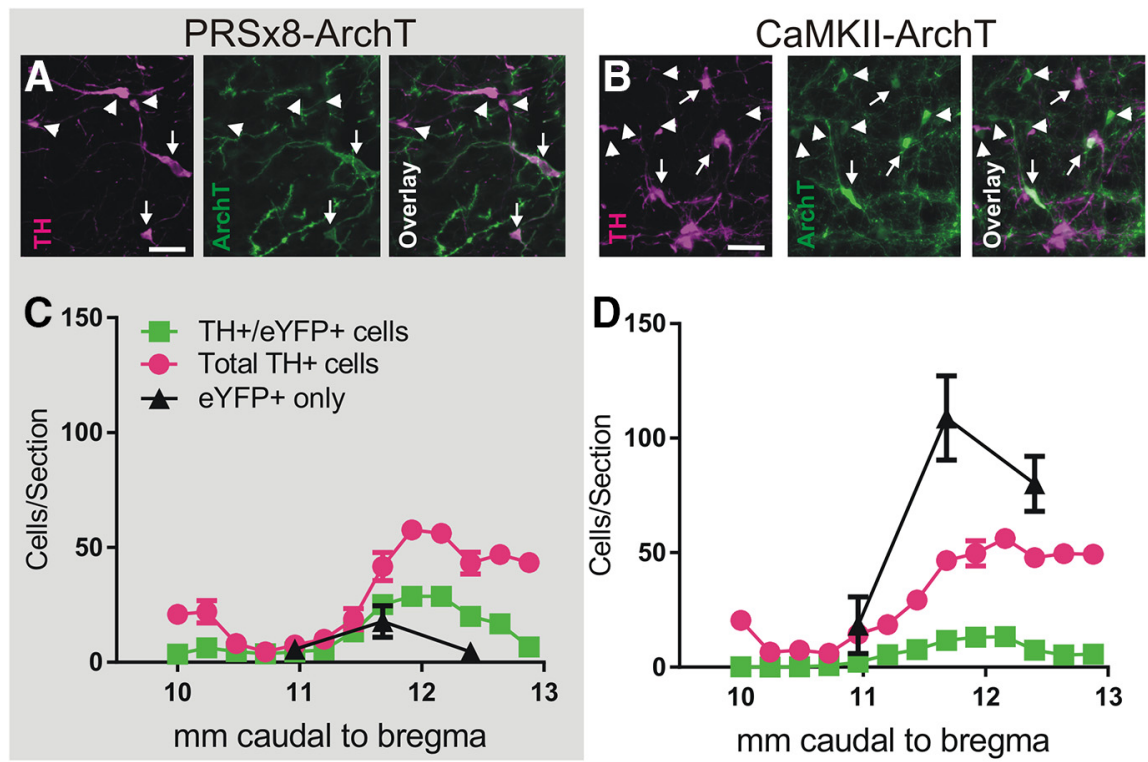

CaMKII-ArchT
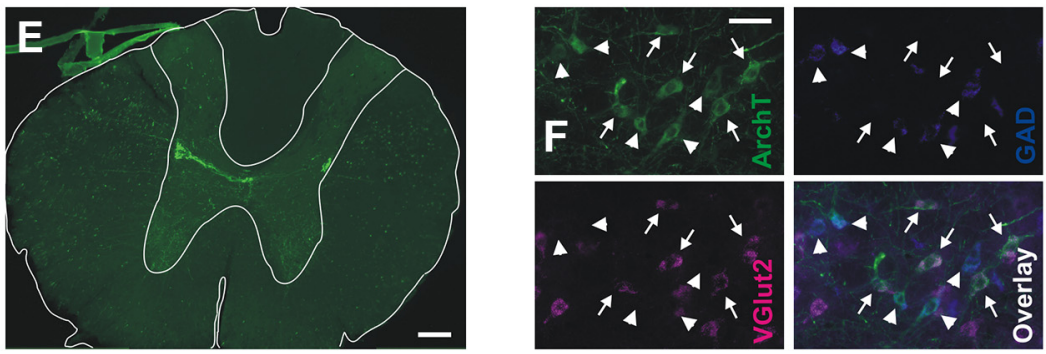

Figure 1. Phenotype and location of ArchT-transduced neurons. A, Example of ArchT-eYFP-expressing C 1 neurons in a transverse section through the medulla oblongata of a rat injected with PRSx8-ArchT (level $\sim 11.9 \mathrm{~mm}$ caudal to bregma). $\boldsymbol{A}$, TH immunoreactivity (magenta), ArchT-eYFP immunoreactivity (green), and overlay. Arrows indicate ArchT-transduced C1 neurons and arrowheads point to $\mathrm{C} 1$ neurons lacking ArchT. Scale bar, $50 \mu \mathrm{m}$. $\boldsymbol{B}$, Example of ArchT-eYFP-expressing $C 1$ neurons in a rat injected with CaMKII-ArchT. Arrows and arrowheads indicate ArchT-transduced C1 neurons and non-C1 neurons, respectively (medullary level, immunohistochemistry, color-coding, and scale bar same as in $\boldsymbol{A}$ ). $\boldsymbol{C}$, Rostrocaudal distribution of total $\mathrm{TH}^{+}$, $\mathrm{TH}^{+} /$eYFP ${ }^{+}$, and eYFP only cells in PRSx8-ArchT-injected rats $(n=7$ rats, neurons $/ 30 \mu \mathrm{m}$ section counted on both sides; every sixth section counted; eYFP only cells were counted at three rostrocaudal levels). $\boldsymbol{D}$. Cell counts of the same 3 classes of neurons in CaMKII-ArchT-injected rats ( $n=7$, neurons/30 $\mu \mathrm{m}$ section counted on both sides; every sixth section counted; eYFP only cells were counted at three rostrocaudal levels). $\boldsymbol{E}$, RVLM neurons transduced with CaMKII-ArchT send dense projections selectively to the intermediolateral (IML) cell column of the spinal cord (transverse section). Scale bar, $200 \mu \mathrm{m}$. $\boldsymbol{F}$, Simultaneous detection of ArchT-eYFP-ir (green), VGlut2 mRNA (magenta), and GAD1 mRNA (blue) in the RVLM of a rat injected with CaMKII-ArchT vector. Glutamatergic neurons (arrows) and GABAergic neurons (arrowheads) were both transduced. Scale bar, $50 \mu \mathrm{m}$.

(Schreihofer and Guyenet, 1997). Most (7/12) barosensitive neurons (5/7 in PRSx8-ArchT-treated rats and 2/5 in CaMKIIArchT-treated rats) were instantly silenced or strongly inhibited ( $>80 \%$ ) by light ( $5-10$ s pulses; gray bars in Fig. $2 A, B)$. When the light was terminated, these neurons were briefly activated (arrowheads in Fig. $2 A, B$ ) before recovering their original firing rate. The other five barosensitive neurons were virtually unaffected by the light pulses $(<10 \%$ firing rate change and no activation when the light was switched off).

The rest of the neurons (45 in PRSx8-ArchT-treated rats and 43 in CaMKII-ArchT-treated rats) were insensitive to BP changes and generally $(56 / 88)$ unaffected by light $(<20 \%$ increase or decrease in discharge rate; Fig. $2 E$ ). However, there were exceptions. In the PRSx8-ArchT rats, four BP-insensitive neurons (three tonically active and one that was respiratory phasic) were $>50 \%$ inhibited by light and another three were activated $>50 \%$ (Fig. $2 E$ ). In the CaMKII-ArchT rats, 15 BP-insensitive neurons were inhibited
$>50 \%$ by light ( 12 tonically active, two respiratory phasic, and one respiratory modulated) and one was $>50 \%$ activated.

Bilateral photoinhibition of CaMKIIArchT-transduced RVLM neurons reduced $\mathrm{BP}$ and SNA reversibly and reproducibly in six chloralose-urethane-anesthetized rats. SNA was reduced by $28.2 \pm 4.8 \%$ under control conditions and by $47.9 \pm 4.9 \%$ when the light was applied, whereas SNA was maximally elevated by deactivating arterial baroreceptors with an intravenous injection of the vasodilator SNP (Sidak's multiple-comparisons test after significant two-way repeated-measures ANOVA; $F_{(1,5)}=9.083, p=0.0296$; Fig. $\left.3 B\right)$. A large burst of SNA was observed consistently (arrows in Fig. $3 A$ ) when the light was terminated before the signal recovered to its preinhibition level.

In summary, in the PRSx8-ArchT rat cohort, the RVLM neurons that were silenced or near silenced by laser light were virtually all barosensitive. These cells were most likely ArchT-transduced C1 neurons based on the tropism of this vector and the histological evidence. In the CaMKII cohort, most lightsensitive neurons were non-barosensitive, consistent with the histological evidence that most CaMKII-ArchT-transduced neurons were not $\mathrm{C} 1$ cells (Fig. 1D).

\section{Hypotension elicited by}

photoinhibiting RVLM neurons is larger under isoflurane anesthesia than in unanesthetized rats

In animals receiving inhalational anesthetics (halothane, isoflurane), RVLMbarosensitive neurons discharge at high rates (up to $35 \mathrm{~Hz}$; Abbott et al., 2009a), probably because powerful inhibitory inputs to these neurons such as those that mediate the baroreflex are inactivated by these anesthetics (Saeki et al., 1996; Umehara et al., 2006). Here, we tested whether the increased discharge rate of RVLMbarosensitive neurons contributes to BP maintenance during anesthesia.

Cardiorespiratory parameters were recorded in high-responder rats that had received bilateral injections of either PRSx8ArchT $(n=7)$ or CaMKII-ArchT $(n=8)$. Light was bilaterally applied to the RVLM (10 s) while the rats were quietly awake or in nonrapid eye movement sleep, as determined by the low variability of $F_{\mathrm{R}}$ and a low breathing rate (between 60 and 80 breaths/ min) (Rostig et al., 2005; Li and Nattie, 2006). The experiment was then repeated on the same day while the rats were anesthetized with isoflurane (1.5-2\%). The entire protocol was implemented under normoxic conditions $\left(21 \% \mathrm{FiO}_{2}\right)$.

In the conscious state, mean arterial pressure (MAP) was $116 \pm 1$ and $107 \pm 1 \mathrm{mmHg}$ and $\mathrm{HR}$ was $286 \pm 9$ and $316 \pm 8$ bpm for PRSx8-ArchT and CaMKII-ArchT transduced rats, respectively (filled circles in Fig. 4C,D). Under isoflurane anesthesia, MAP decreased to $106 \pm 2$ and $92 \pm 3 \mathrm{mmHg}$ for PRSx8- 

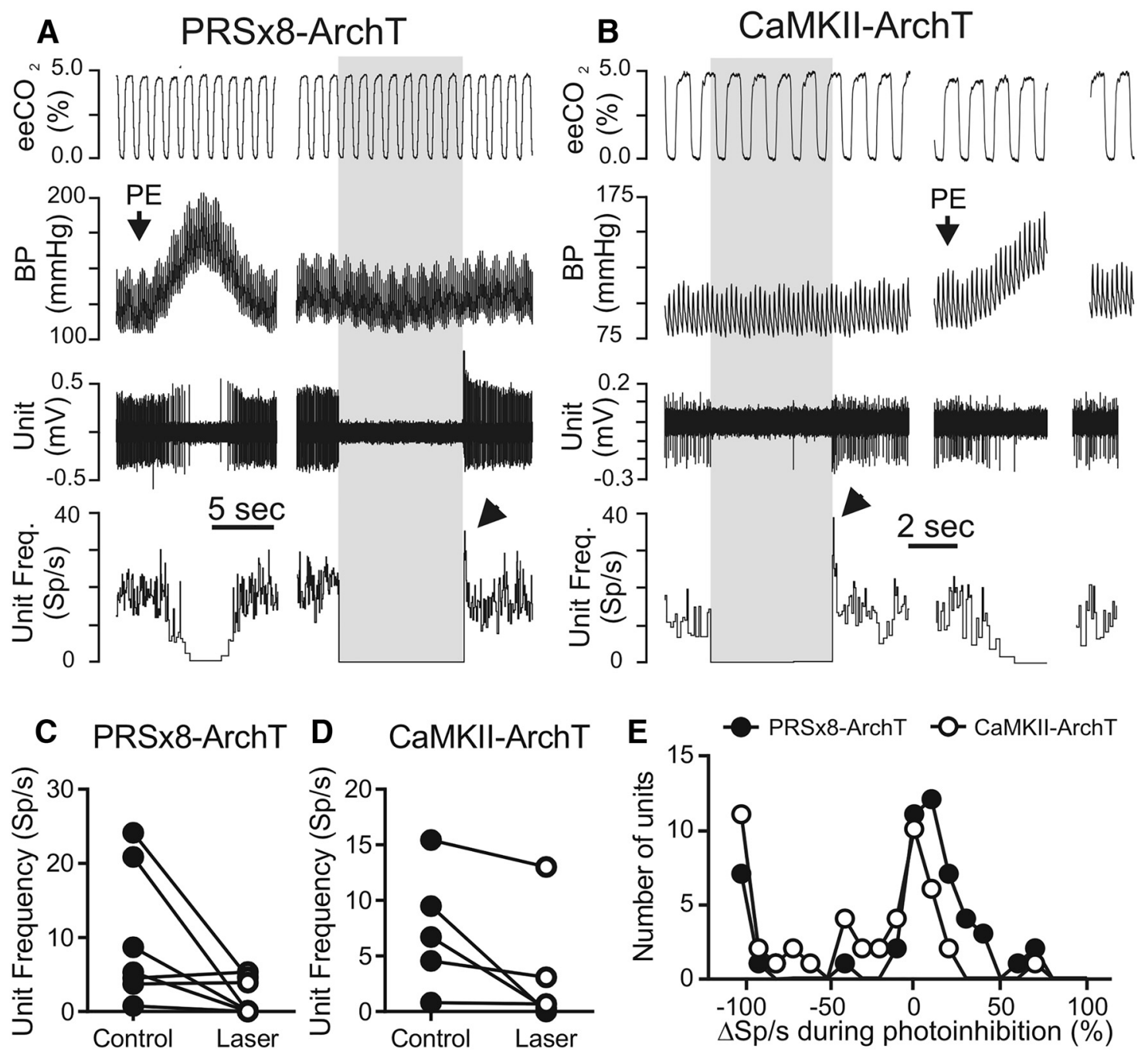

Figure 2. Effect of ArchT photoactivation on the discharge of RVLM neurons. $\boldsymbol{A}$, Single RVLM-barosensitive unit recorded in an $\alpha$-chloralose/urethane anesthetized rat previously injected unilaterally with PRSx8-ArchT.The unit was $100 \%$ inhibited by raising BP with an intravenous injection of phenylephrine (PE, arrow) and silenced by $532 \mathrm{~nm}$ laser light (gray bar; $5 \mathrm{~mW} ; 10 \mathrm{~s}$ ). From top to bottom, End-expiratory $\mathrm{CO}_{2}\left(\mathrm{eeCO}_{2}\right)$, arterial BP, RVLM unit, and unit discharge rate. $\boldsymbol{B}$, Identical experiment in a rat injected with CaMKII-ArchT. This RVLM-barosensitive neuron was also silenced by laser light (gray bar). In both cases, light-induced inhibition was followed by a brief rebound (arrowhead). $C$, Effect of light in seven barosensitive RVLM units recorded in animals injected with PRSx8-ArchT. D, Effect of light in five barosensitive RVLM units recorded in animals injected with CaMKII-ArchT. E, Distribution histogram representing the light-evoked change in unit activity of all RVLM neurons recorded: number of neurons are plotted versus the percentage change in unit activity binned in 10\% increments from $-100 \%$ (silenced units) to $+100 \%$.

ArchT and CaMKII-ArchT, respectively (Fig. 4C; Sidak's multiple-comparisons test after significant two-way repeatedmeasures ANOVA; $F_{(1,6)}=59.4, p=0.0003$ and $F_{(1,8)}=25.58$, $p=0.0010$, for PRSx8-ArchT and CaMKII-ArchT, respectively) and HR increased to $331 \pm 11$ and $335 \pm 10 \mathrm{mmHg}$ for PRSx8ArchT and CaMKII-ArchT, respectively (Fig. 4D; $p<0.0001$ for both groups; Sidak's multiple-comparisons test after significant two-way repeated-measures ANOVA; HR: $F_{(1,6)}=13.78, p=$ 0.0099 and HR: $\left.F_{(1,8)}=14.78, p=0.0049\right)$. Under isoflurane anesthesia, resting breathing slowed to $53.0 \pm 3.8$ and $49.6 \pm 1.6$ bpm for PRSx8-ArchT and CaMKII-ArchT groups, respectively, compared with $67.5 \pm 3.8$ and $68.3 \pm 3.1 \mathrm{bpm}$ during the conscious state (Fig. $4 E ; p<0.01$ and $p<0.0001$; Sidak's multiplecomparisons test after significant two-way repeated-measures ANOVA; $F_{(1,6)}=3.654, p=0.1045$ and $F_{(1,8)}=24.74, p=0.0011$ for PRSx8-ArchT and CaMKII-ArchT, respectively).

During anesthesia, photoinhibition of RVLM neurons produced a larger BP drop $(-14.66 \pm 2.06$ and $-14.29 \pm 0.87$ $\mathrm{mmHg}$ for PRSx8-ArchT and CaMKII-ArchT, respectively; Fig. $5 A)$ than in the conscious state $(-3.7 \pm 1.0$ and $-4.5 \pm 0.6$
mmHg for PRSx8-ArchT and CaMKII-ArchT, respectively; $p<$ 0.01 for both groups; Dunn's multiple-comparisons test after significant Kruskal-Wallis test; $\mathrm{H}=24.04, p<0.0001)$. Under isoflurane, RVLM neuronal inhibition decreased HR slightly $(-3.6 \pm 1.0$ and $-7.4 \pm 0.6 \mathrm{mmHg}$ for PRSx8-ArchT and CaMKII-ArchT, respectively), whereas HR increased in the conscious state $(+5.2 \pm 1.9$ and $+3.7 \pm 1.2 \mathrm{bpm}$, respectively; $p<$ 0.01 for both groups; Dunn's multiple-comparisons test after significant Kruskal-Wallis test; $\mathrm{H}=26.8, p<0.0001$; Fig. $5 B$ ). In the PRSx8-ArchT cohort, both $F_{\mathrm{R}}$ and $V_{\mathrm{T}}$ decreased during ArchT photoactivation in both the conscious and anesthetized states (Fig. 5C,D). In contrast, CaMKII-ArchT rats experienced statistically significant different $F_{\mathrm{R}}$ responses during neuronal inhibition; increased $F_{\mathrm{R}}$ during conscious state and smaller inhibition during isoflurane $(p<0.0001$ and $p=0.0418$ for conscious and isoflurane, respectively; Sidak's multiplecomparisons test after significant two-way repeated-measures ANOVA; $F_{(1,28)}=34.47, p<0.0001$; Fig. $5 C$ ). Although similar drops in $V_{\mathrm{T}}$ were experienced by both groups of rats during neuronal inhibition in conscious conditions, neuronal inhibition in 

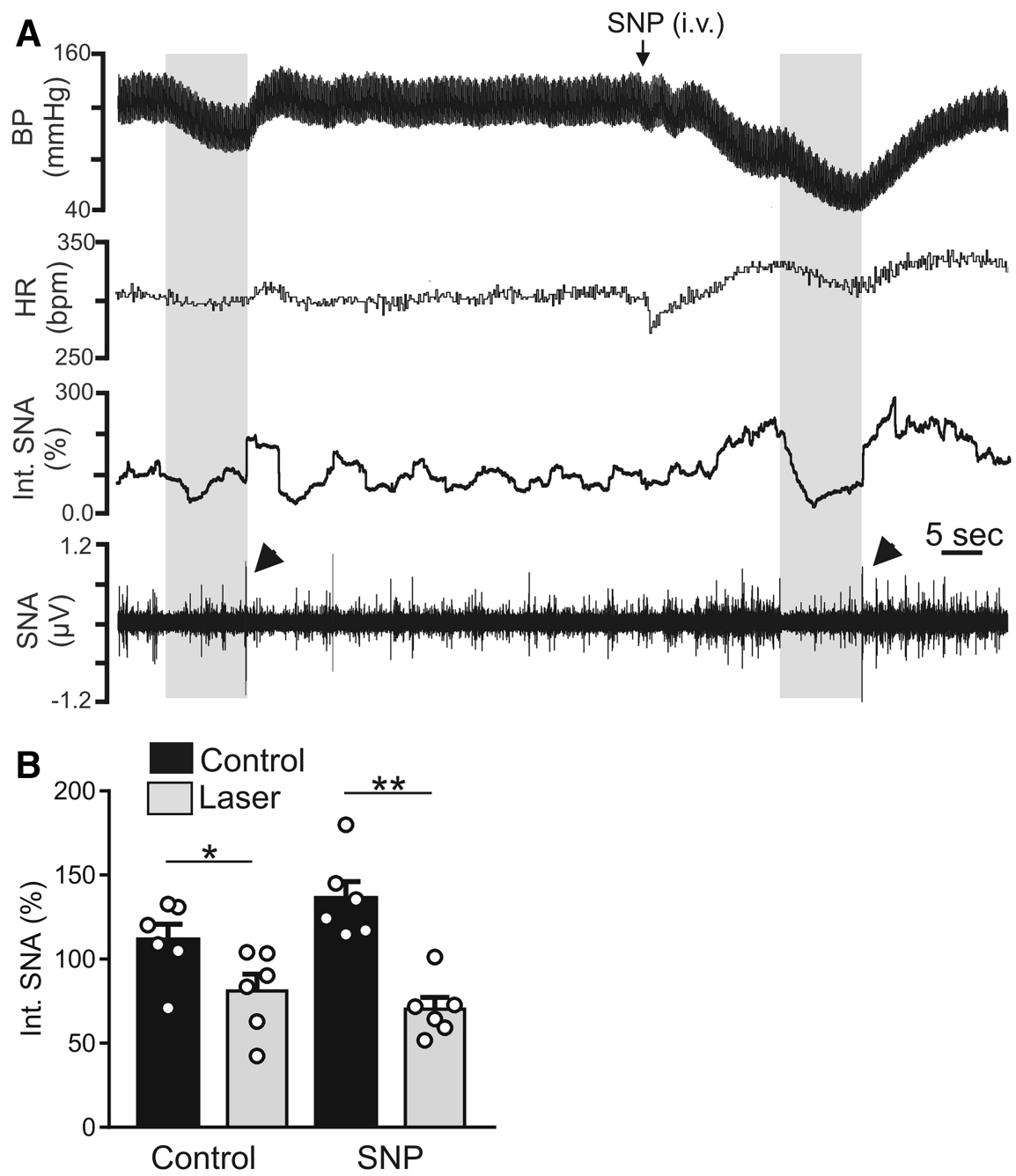

Figure 3. Proton pump activation in RVLM suppresses SNA in anesthetized rats. $A$, Hypotension and inhibition of splanchnic SNA elicited by light (532 nm, $7 \mathrm{~mW}$, applied for $10 \mathrm{~s}$ bilaterally at gray bars) in an $\alpha$-chloralose/urethane anesthetized rat previously injected with CaMKII-ArchT. Traces from top to bottom, Arterial BP, HR, SNA (raw trace), and integrated SNA (Int SNA, $2 s$ time constant). SNA inhibition was modest at resting BP and enhanced when SNA was elevated by intravenous administration of sodium nitropusside (SNP, arrow). Arrowheads indicate SNA rebound immediately after the light was turned off. $\boldsymbol{B}$, Group data $(n=6)$ depicting Int SNA before and during RVLM illumination under control conditions and shortly after intravenous injection of SNP. ${ }^{*} p<0.05 ;{ }^{* *} p<0.01$.

CaMKII-ArchT rats produced an increase in $V_{\mathrm{T}}$ under isoflurane ( $p=0.1512$ and $p=0.0036$ for conscious and isoflurane, respectively; Sidak's multiple-comparisons test after significant twoway repeated-measures ANOVA; $F_{(1,28)}=18.05, p=0.0002$; Fig. $5 D)$.

In sum, these experiments suggest that BP is maintained near normal levels under isoflurane anesthesia by an increased activity of RVLM neurons, particularly of the $\mathrm{C} 1$ variety.

\section{Relationship between hypotension and proportion of} ArchT-transduced C1 neurons

The preceding results were obtained in the subset of highresponders (7/20 rats injected with $\mathrm{PRSx} 8$-ArchT and 8/12 rats injected with CaMKII-ArchT). When the entire cohort of PRSx8ArchT-injected animals was examined, we found a significant correlation between the light-induced hypotension and the proportion of $\mathrm{C} 1$ neurons transduced $\left(R^{2}=0.57\right.$; Fig. $\left.6 A\right)$. The plot suggests the existence of a threshold effect whereby a minimum of $20 \% \mathrm{C} 1$ neurons need to be transduced to elicit a detectable hypotensive response.

Fewer C1 neurons were transduced overall in the CaMKII-ArchT cohort and there was no correlation between the number of $\mathrm{C} 1$ neurons transduced and the light-induced BP drop under isoflurane $\left(R^{2}=0.01\right.$; Fig. $\left.6 B\right)$. The absence of correlation could merely reflect that the number of transduced $\mathrm{C} 1$ neurons was very similar in all rats.

Finally, we compared the BP responses elicited in 5 PRSx8-ArchT and 5 CaMKIIArchT animals with similar percentages of C1 neurons transduced $(27.2 \pm 0.4 \%$ and $26.8 \pm 0.9 \%$ for PRSx 8 and CaMKII groups, respectively). The response observed in the CaMKII-ArchT cohort was larger than in the PRSx8-ArchT rats $(12.8 \pm 1.6 \mathrm{mmHg}$ for CaMKII and $5.9 \pm 1.2 \mathrm{mmHg}$ for PRSx8 groups; $p=0.009$, unpaired $t$ test).

Rebound of neuronal action potentials, SNA, and BP is observed immediately after ArchT inhibition

In urethane/chloralose-anesthetized rats, RVLM-barosensitive units were activated transiently immediately after the end of the light pulse and a large burst of SNA was observed consistently during the same time period (arrowheads in Figs. 2, 3; expanded scale illustrations in Fig. $7 A, B$ ). In unanesthetized rats, $\mathrm{BP}$ rose immediately after the laser light was terminated (arrowheads in Fig. 4; expanded scale illustration in Fig. 7C). Event-triggered averages (Fig. 7D) of these rebound phenomena indicated that the onset of the burst of activity of RVLM neurons preceded the onset of the SNA burst by $20 \mathrm{~ms}(41 \pm 14$ and $61 \pm 4$ ms delay from laser-off for unit and SNA, respectively) and the onset of the BP rise by $711 \mathrm{~ms}$ $(41 \pm 14$ and $752 \pm 25$ ms delay from laseroff for unit and MAP, respectively). These latency differences suggest that the postillumination rebound of SNA and BP could result from the after inhibitory rebound of the activity of RVLM-barosensitive neurons.

Photoinhibition of RVLM produces greater hypotension during hypoxia than during normoxia or hypercapnia in PRSx8-ArchT-treated rats

In anesthetized or reduced preparations, both hypoxia and hypercapnia activate bulbospinal-barosensitive RVLM neurons with postulated sympathoexcitatory function (Sun and Reis, 1993; Moreira et al., 2006). The effect of hypoxia is attributed principally to a polysynaptic input from the carotid bodies and that of $\mathrm{CO}_{2}$ mostly to central cardiorespiratory coupling; that is, input from the respiratory pattern generator to RVLMbarosensitive neurons, C1 cells included (Guyenet, 2014).

To test whether the $\mathrm{C} 1$ cells contribute to BP stability during hypoxia, we examined the cardiorespiratory changes evoked by photoactivating ArchT bilaterally in rats exposed, in random order, to four levels of $\mathrm{FiO}_{2}$ (fraction inspired oxygen: 65\%, 21\%, 

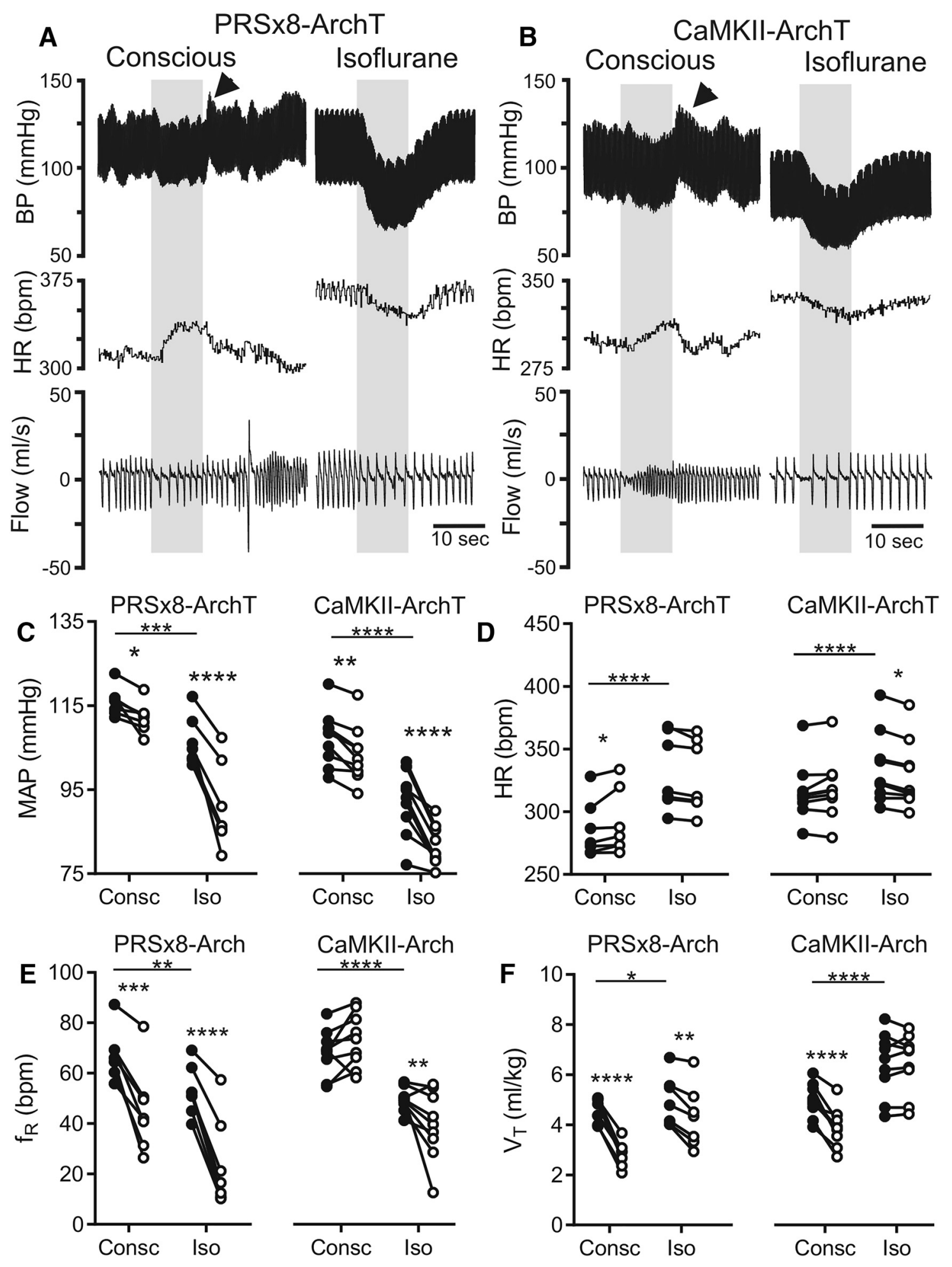

Figure 4. Hypotension elicited by RVLM neuron inhibition is much larger in isoflurane-anesthetized rats than in conscious rats. $A$, Example recordings of BP, HR, and respiratory flow (Flow) from a rat previously injected with PRSx8-ArchT ( $\boldsymbol{A}$ ) and CaMKII-ArchT $(\boldsymbol{B})$. Bilateral inhibition of RVLM neurons (gray bars) by ArchT had very little effect on BP in the absence of anesthetic (conscious state), but produced profound hypotension under $\sim 2 \%$ isoflurane anesthesia. In both rats, Arch photoinhibition resulted in mild tachycardia in conscious rats and mild bradycardia under isoflurane. Respiratory responses were quite different between PRSx8-ArchT and CaMKII-ArchT rats. The former experienced decreased $F_{\mathrm{R}}$ and $V_{T}$ in both conditions, whereas the latter increased $F_{\mathrm{R}}$ in the conscious state. Arrowheads indicate rebound in BP after cessation of ArchT photoinhibition. $\boldsymbol{C}-\boldsymbol{F}$, Data for all experimental animals $\left(n=7\right.$ for PRSx8-ArchT and $n=9$ for CaMKII-ArchT) for MAP $(\boldsymbol{C}), \operatorname{HR}(\boldsymbol{D}), F_{\mathrm{R}}(\boldsymbol{E})$, and $V_{\mathrm{T}}(\boldsymbol{F})$. Filled circles: 10 s before before bilateral ArchT photoactivation; open circles: during bilateral inhibition with ArchT. ${ }^{*} p<0.05,{ }^{* *} p<0.01,{ }^{* * *} p<0.001$, and ${ }^{* * * *} p<0.0001$.

$15 \%, 12 \%$, and $10 \%)$. The effects of hypercapnia were examined by exposing the rats to $3 \%$ and $6 \% \mathrm{FiCO}_{2}$ in $21 \% \mathrm{O}_{2}$.

A representative animal illustrates the principal findings (Fig. $8 A$ ). For clarity, this panel illustrates only normoxia, one hypoxia level $\left(12 \% \mathrm{FiO}_{2}\right)$ and one hypercapnia level $\left(6 \% \mathrm{FiCO}_{2}\right.$ in $\left.21 \% \mathrm{O}_{2}\right)$. In normoxia, bilateral inhibition of ArchT-transduced RVLM neurons produced a small BP drop followed by a rebound increase, decreased HR slightly, and reduced breathing (both $F_{\mathrm{R}}$ and $V_{\mathrm{T}}$ ). 

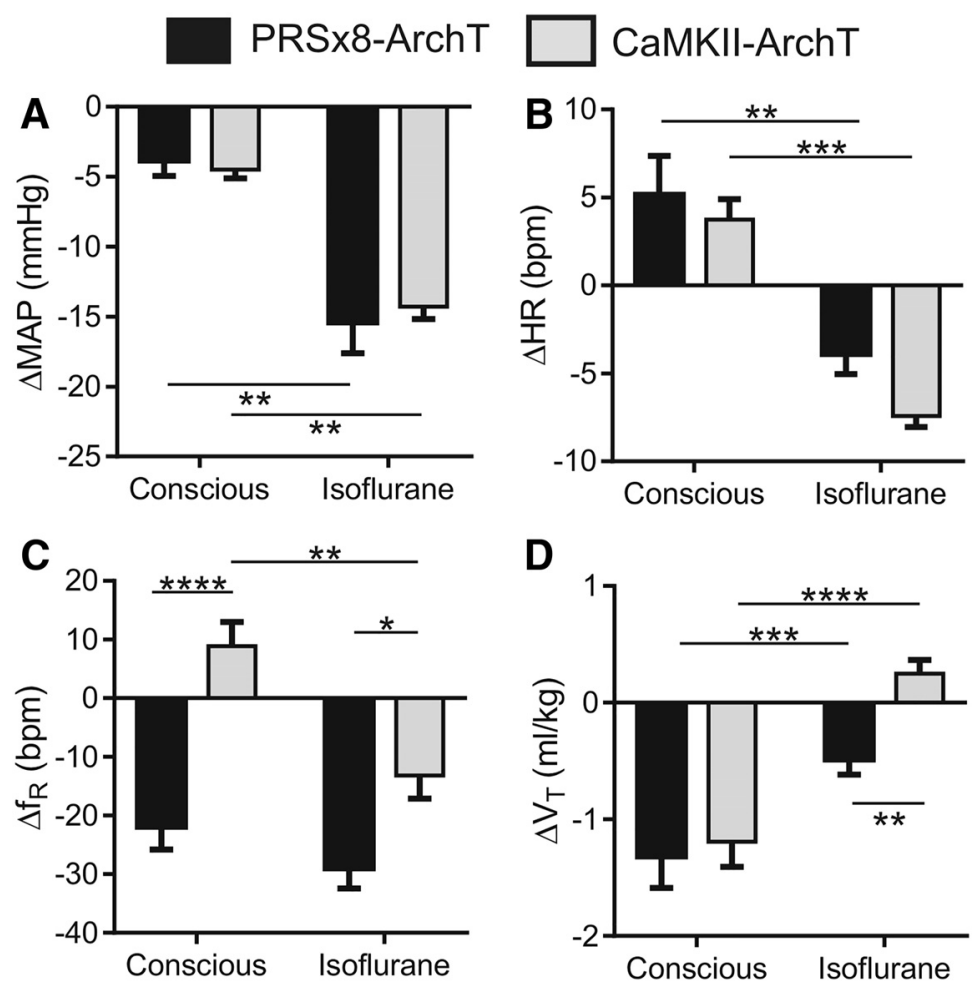

Figure 5. Effect of ArchT photoactivation on cardiorespiratory variables in conscious or anesthetized rats: comparison between animals injected with CaMKII-ArchT vs PRSx8-ArchT. $\boldsymbol{A}-\boldsymbol{D}$, Average changes induced by proton pump activation $(n=7$ for PRSx8-ArchT and $n=9$ for CaMKIII-ArchT). MAP $(\boldsymbol{A}), \operatorname{HR}(\boldsymbol{B}), F_{\mathrm{R}}(\boldsymbol{C})$, and $V_{\mathrm{T}}(\boldsymbol{D})$ for rats injected with PRSx8-ArchT (black bars) and CaMKII-ArchT (gray bars).

\section{A PRSx8-ArchT}

\section{Transduced $\mathrm{C} 1$ neurons (\%)}
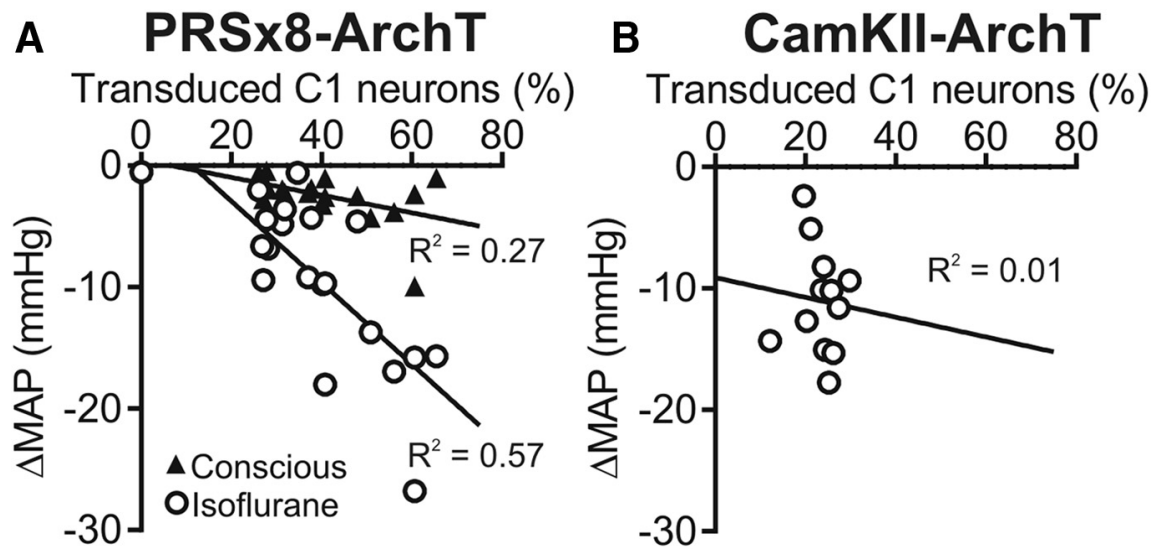

Figure 6. Effect of ArchT photoactivation on MAP with varying levels of viral transduction in 1 neurons. $A$, Correlation between percentage C1 neurons transduced with PRSx8-ArchT and hypotension elicited by ArchT photoactivation ( $n=20$ rats, 7 highresponders and 13 other rats tested with low responses; $C 1$ neurons counted between transverse planes 11.6 and $12.1 \mathrm{~mm}$ caudal to bregma; black triangles, unaesthetized rats; open circles: same rats during isoflurane anesthesia). $\boldsymbol{B}$, Lack of correlation between percentage C 1 neurons transduced with CaMKII-ArchT and hypotension elicited by ArchT photoactivation ( $n=12$ rats, 9 highresponders and 3 other rats tested with low responses). ${ }^{*}$, ${ }^{* *}$, ${ }^{* *}$ and ${ }^{* * *}$ indicate ${ }^{*} p<0.05,{ }^{* *} p<0.01,{ }^{* *} p<0.001$, and **** $p<0.0001$.

Hypoxia produced a negligible change in resting BP and HR in this rat and elicited the expected increase in breathing rate. Inhibition of ArchT-transduced RVLM neurons under hypoxic conditions produced a large drop in BP, but no breathing change. Hypercapnia $\left(\mathrm{FiO}_{2} 21 \%, \mathrm{FiCO}_{2} 6 \%\right)$ had a negligible effect on resting $\mathrm{BP}$ and $\mathrm{HR}$, but increased breathing substantially (both rate and amplitude). Inhibition of ArchT-transduced neurons during hypercapnia produced a massive breathing reduction, but the BP drop was only marginally larger than when the rat was breathing room air.
Figure $8, B-E$, illustrates the group data (7 rats). Under resting conditions (light off) $F_{\mathrm{R}}$ was significantly increased during hypoxia $\left(\mathrm{FiO}_{2} 12\right.$ or $10 \%$; $p<0.0001$ for hypoxia; Sidak's multiple-comparisons test after significant two-way repeated-measures ANOVA; $F_{(4,24)}=24.34, p<0.0001$; Fig. $8 D)$ and normoxic hypercapnia $\left(\mathrm{FiCO}_{2}\right.$ to 3 or $6 \%$; $p<0.0001$ for hypercapnia; Sidak's multiple-comparisons test after significant two-way repeated-measures ANOVA; $F_{(2,12)}=22.32, p<0.0001$; Fig. $8 D)$, with the more extreme conditions $\left(\mathrm{FiO}_{2}\right.$ to $10 \%$ or $\mathrm{FiCO}_{2}$ to $6 \%$ ) resulting in a near doubling of $F_{\mathrm{R}}$. Hypercapnia (3\% and $6 \%)$ also produced significant increases in $V_{\mathrm{T}}$, whereas hypoxia did not $(p<0.0001$ for hypercapnic conditions; Sidak's multiplecomparisons test after significant two-way repeated-measures ANOVA; $F_{(2,12)}=$ 5.275, $p=0.0227$; Fig. $8 E$ ). Hypoxia reduced resting MAP by $6.1 \pm 1.7$ and $14.3 \pm$ $2.0 \mathrm{mmHg}$ at $12 \% \mathrm{FiO}_{2}$ and $10 \% \mathrm{FiO}_{2}$, respectively $(p=0.0049$ and $p=0.0001$ respectively; Sidak's multiple-comparisons test after significant two-way repeatedmeasures ANOVA; $F_{(4,24)}=31.86 ; p<$ 0.0001; Fig. $8 B$ ). Resting MAP was not significantly altered by hypercapnia $\left(\mathrm{FiCO}_{2}\right.$ of $3 \%$ or $\left.6 \% ; F_{(2,12)}=0.18, p=0.8376\right)$. Hypoxia $\left(15 \% \mathrm{FiO}_{2}\right)$ increased $\mathrm{HR}(23.9 \pm 10.5$ bpm), whereas $10 \% \mathrm{FiO}_{2}$ did the opposite $(17.3 \pm 8.1 \mathrm{bpm})(p<0.0001$; Sidak's multiple-comparisons test after significant twoway repeated-measures ANOVA; $F_{(4,24)}=$ 20.16, $p<0.0001)$. Hypercapnia reduced $\mathrm{HR}$ by13.4 $\pm 7.8 \mathrm{bpm}$ at $6 \% \mathrm{FiCO}_{2}$ only $(p<0.0001$; Sidak's multiple-comparisons test after significant two-way repeatedmeasures ANOVA; $F_{(2,12)}=8.804, p=$ 0.0044; Fig. 8C).

ArchT photoactivation produced a considerably larger BP drop in hypoxia than normoxia $(-21.9 \pm 2.9 \mathrm{mmHg}$ at $10 \% \mathrm{FiO}_{2}$ and $-22.4 \pm 3.3 \mathrm{mmHg}$ at $12 \%$ $\mathrm{FiO}_{2}$ compared with $-3.8 \pm 1.1 \mathrm{mmHg}$ at $21 \% \mathrm{FiO}_{2} ; p<0.001$ for both conditions; Dunn's multiple-comparisons test after significant Kruskal-Wallis test; $\mathrm{H}=$ 50.51, $p<0.0001$; Fig. 9A). The tachycardia during ArchT activation observed under normoxia $(+5.2 \pm 2.2 \mathrm{bpm})$ was converted into a mild bradycardia in hypoxia $\left(-20.0 \pm 3.0 \mathrm{bpm}\right.$ at $10 \% \mathrm{FiO}_{2}$ and $-17.5 \pm 5.6 \mathrm{mmHg}$ at $12 \% \mathrm{FiO}_{2} ; p<0.0001$ for both conditions; Sidak's multiple-comparisons test after significant two-way repeated-measures ANOVA; $F_{(3,39)}=40.65, p<0.0001$; Fig. $9 B$ ). ArchT photoactivation produced a significantly, albeit marginally larger, $\mathrm{BP}$ drop under $6 \% \mathrm{FiCO}_{2}$ than in room air $(-7.2 \pm$ 0.8 vs $-3.8 \pm 1.1 \mathrm{mmHg} ; p=0.001$ Sidak's multiplecomparisons test after significant two-way repeated-measures ANOVA: $F_{(2,26)}=18.2, p<0.0001$; Fig. $\left.9 A\right)$. The light-induced breathing reduction (decreased $F_{\mathrm{R}}$ and $V_{\mathrm{T}}$ ) disappeared under 

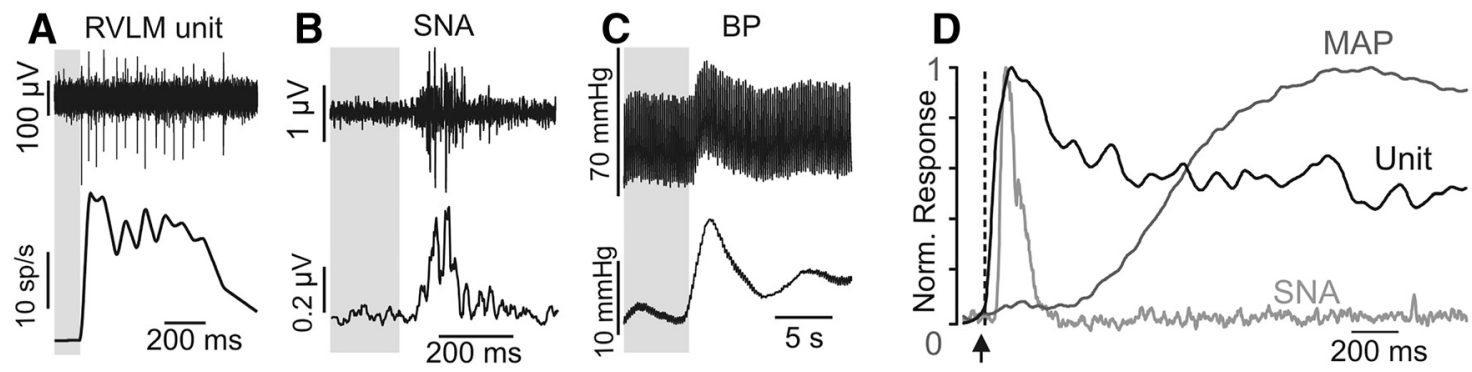

Figure 7. Rebound of $\mathrm{C} 1$ unit activity, splanchnic SNA, and BP after RVLM illumination. $\boldsymbol{A}-\boldsymbol{C}$, Effect of unilateral $(\boldsymbol{A})$ or bilateral $(\boldsymbol{B}, \boldsymbol{C})$ RVLM illumination in rats previously injected with ArchT-expressing vectors. Gray bars represent the final portion of a 10 sillumination period. $\boldsymbol{A}$, Postinhibitory rebound of a representative barosensitive neuron (presumptive $C 1$ cell) that was silenced by light. Top trace, Raw signal. Bottom trace, Instantaneous action potential frequency ( $\alpha$-chloralose anesthetized rat). $\boldsymbol{B}$, postinhibitory rebound of SNA ( $\alpha$-chloralose anesthetized rat). Top trace, Raw SNA. Bottom trace, Rectified and integrated signal (5 ms time constant). C, Postinhibitory rebound of BP in a conscious rat. Top, Raw signal. Bottom, Smoothed signal (1 s time constant). D, Average time course multiple experiments as in A-C of postinhibitory rebound for neuronal unit activity ( $n=6$ units from 2 each PRSX8- or CaMKIl-ArchT-injected rats, total 4 rats), rectified/integrated SNA ( $n=7$ CaMKII-ArchT injected rats), and MAP ( $n=9$ CaMKII-injected rats).

hypoxia, but was amplified during hypercapnia (Fig. 9C,D). These breathing effects have been previously attributed to the inhibition of RTN neurons.

\section{Photoinhibition of RVLM neurons during hypoxia and hypercapnia in CaMKII-ArchT-treated rats: similarity and differences with PRSx8-ArchT treated rats}

The cohort of high-responder rats bilaterally injected with CaMKII-ArchT $(n=8)$ were subjected to the same inspired gas levels as described above for the PRSx8-ArchT rats. In Figure 9, the effects of neuronal inhibition using this more ubiquitous neuronal promoter are compared with those obtained with PRSx8-ArchT. In the CaMKII-ArchT rats, ArchT photoactivation (10 s) during normoxia produced a small tachycardia and a small BP drop followed by a rebound (see Fig. $4 B$ for example), as in PRSx8-ArchT-treated rats. Photoactivation of the proton pump produced a much larger hypotension during hypoxia ( $p=$ 0.0028 comparing $\mathrm{FiO}_{2} 21 \%$ and 12\%; Dunn's multiplecomparisons test after significant Kruskal-Wallis test; $\mathrm{H}=50.51$, $p<0.0001$; Fig. 9A). The tachycardic response during normoxia was converted into a small bradycardia in hypoxia $(p<0.0001$ comparing $\mathrm{FiO}_{2}$ 21\% and 12\%; Sidak's multiple-comparisons test after significant two-way repeated-measures ANOVA; $F_{(3,39)}=40.65, p<0.0001$; Fig. $\left.9 B\right)$. Under $6 \% \mathrm{FiCO}_{2}$, the hypotension due to ArchT activation was significantly larger than $0 \%$ $\mathrm{FiCO}_{2}(-6.2 \pm 0.9$ and $-4.6 \pm 0.7 \mathrm{mmHg}$, respectively; $p=$ 0.0346; Sidak's multiple-comparisons test after significant twoway repeated-measures ANOVA: $F_{(2,26)}=15.73, p<0.0001$; Fig. $9 A$ ), although still much smaller than produced during hypoxia.

The major differences between PRSx8-ArchT-treated rats and the rats receiving CaMKII-ArchT concerned the $F_{\mathrm{R}}$ response (Fig. $9 C)$. In the former group, ArchT activation reduced $F_{\mathrm{R}}$ in all conditions (all $\mathrm{FiO}_{2}$ and $\mathrm{FiCO}_{2}$ levels) except hypoxia. In the latter group, ArchT activation increased $F_{\mathrm{R}}$ in all conditions except hyperoxia. Activation of ArchT had significantly different effects on $F_{\mathrm{R}}$ across gas levels tested for both PRSx8-ArchT (twoway repeated-measures ANOVA; $F_{(6,36)}=47.81, p<0.0001$; Fig. 9E) and CaMKII-ArchT rats (two-way repeated-measures ANOVA; $F_{(6,36)}=14.13, p<0.0001$; Fig. $\left.9 F\right) . * * * * * *$

In summary, the cardiovascular changes produced by proton pump activation were very similar in CaMKII-ArchT rats and PRSx8-ArchT animals, but opposite effects on breathing were elicited.

\section{Hypercapnia attenuates the effects of hypoxia}

These experiments were conducted in the 7 PRSx8-ArchT highresponders. Hypoxia $\left(10 \% \mathrm{FiO}_{2}\right)$ reduced resting MAP from
$116 \pm 1$ to $102 \pm 2 \mathrm{mmHg}$ and $\mathrm{HR}$ from $286 \pm 9$ to $269 \pm 8 \mathrm{bpm}$ as noted above (Fig. 8). Addition of $3 \% \mathrm{CO}_{2}\left(10 \% \mathrm{FiO}_{2}\right.$ and $3 \%$ $\left.\mathrm{FiCO}_{2}\right)$ restored MAP and $\mathrm{HR}(112 \pm 2 \mathrm{mmHg}$ and $284 \pm 6 \mathrm{bpm}$, respectively) back to control levels (Fig. $10 A-C$ ) and further increased ventilation, mainly via a rise in $V_{\mathrm{T}}$ (filled circles in Fig. $10 D, E)$.

Adding $\mathrm{CO}_{2}$ attenuated the changes in MAP and HR elicited by ArchT photoactivation during hypoxia. The light-induced hypotension was reduced from $-21.9 \pm 2.9 \mathrm{mmHg}$ to $-12.1 \pm 2.1$ mmHg $(p<0.05$; Sidak's multiple-comparisons test after significant one-way repeated-measures ANOVA; $F=25.12, p<$ 0.0006; Fig. $10 A, B)$. The bradycardia $(-20.0 \pm 3.0 \mathrm{bpm})$ was converted into a small tachycardia $(+2.2 \pm 2.0 \mathrm{bpm})$ by adding $\mathrm{CO}_{2}(p<0.01$; Sidak's multiple-comparisons test after significant one-way repeated-measures ANOVA; $F=28.37, p<$ 0.0009; Fig. $10 \mathrm{~A}, \mathrm{C}$ ). Adding $3 \% \mathrm{CO}_{2}$ to the hypoxic mixture also restored the breathing inhibition elicited by ArchT activation (Fig. $10 A, C, D)$.

These results suggest that the addition of a small percentage of $\mathrm{CO}_{2}$ to the hypoxic mixture actually reduced the activation of the $\mathrm{C} 1$ neurons despite a further increase in ventilation. The beneficial effect of hypercapnia most likely derives from increased ventilation improving blood oxygenation (Basting et al., 2015).

\section{Hypotension elicited by photoinhibition of RVLM neurons is enhanced after baroreceptor denervation}

C1 and other RVLM BP regulating neurons are tonically inhibited by medullary GABAergic interneurons that are in turn driven by arterial baroreceptors (Schreihofer and Guyenet, 2003). The low contribution to BP these neurons exhibit at rest (Figs. 4, 5) could be due to this inhibitory input. To test this hypothesis, we used six of the seven PRSx8-ArchT high-responders; half were subjected to SAD and the rest underwent sham surgery. We recorded resting BP and HR and the effect of $10 \mathrm{~s}$ ArchT photoactivation on these parameters 48 and $24 \mathrm{~h}$ before surgery and on multiple days after surgery, up to $20 \mathrm{~d}$ postoperatively (Fig. 11). SAD animals were significantly hypertensive the day after surgery, but normotensive on day three after surgery (MAP presurgery: $118 \pm 4 \mathrm{mmHg}$; day $+1: 146 \pm 13 \mathrm{mmHg}$; day $+3: 116 \pm 3$ mmHg; $p<0.05$ for day +1 ; Sidak's multiple-comparisons test after significant two-way repeated-measures ANOVA; main effect of time on MAP $F_{(7,16)}=15.95, p<0.0001$; Fig. $\left.11 A, B\right)$. HR was significantly elevated $24 \mathrm{~h}$ after SAD (from $299 \pm 21$ to $446 \pm$ $20 \mathrm{bpm} ; p<0.0001$ for day +1 ; Sidak's multiple-comparisons test after significant two-way repeated-measures ANOVA; main effect of time on $\operatorname{HR} F_{(7,16)}=7.224, p=0.0005$; Fig. $\left.5 A, C\right)$ and 
A

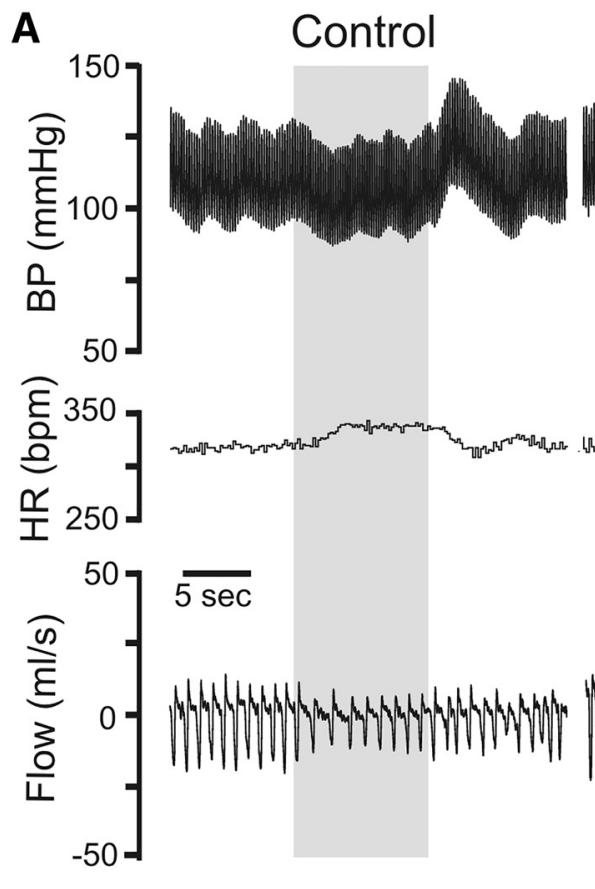

Hypoxia

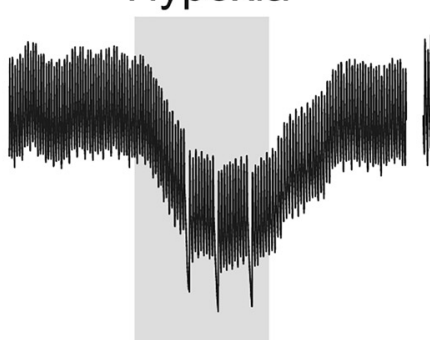

Hypercapnia

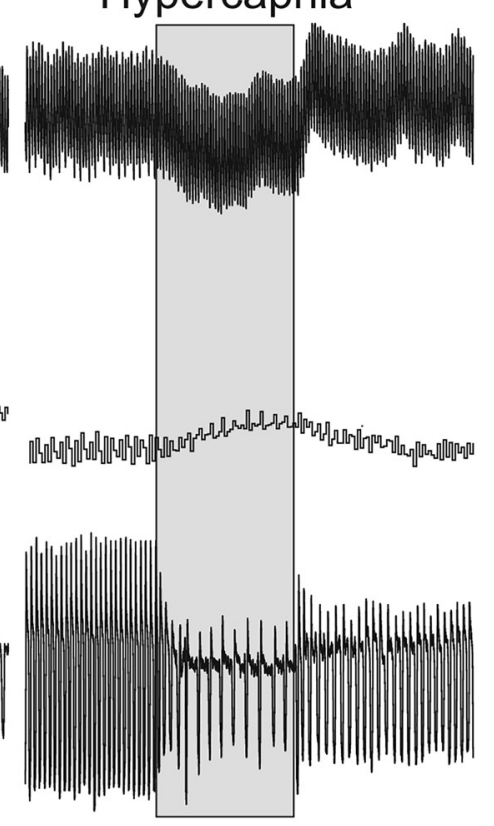

- Control

C

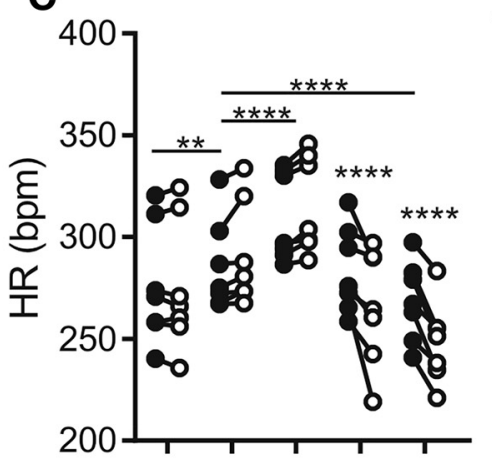

-O-Laser

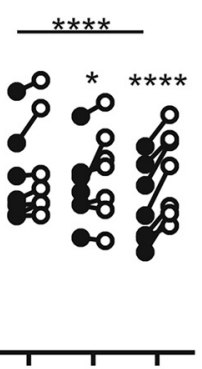

E

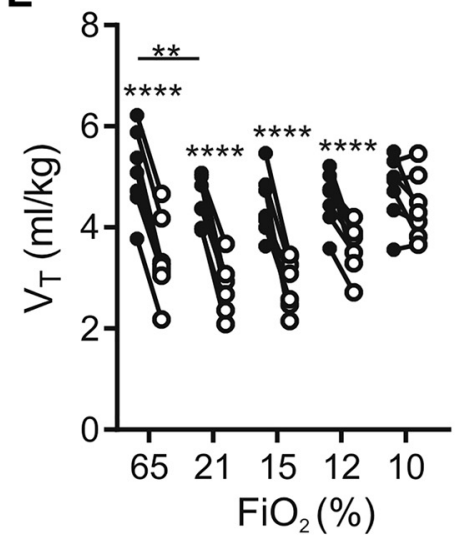

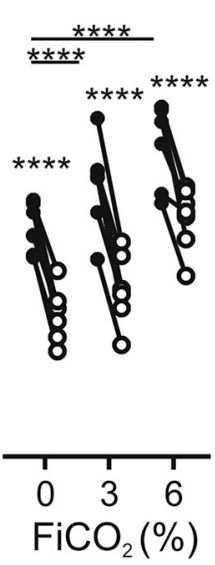

Figure 8. Light elicits large BP reductions in unanesthetized PRSx8-ArchT injected rats exposed to hypoxia but not hypercapnia. $A$, BP, HR, and respiratory flow (Flow) in a

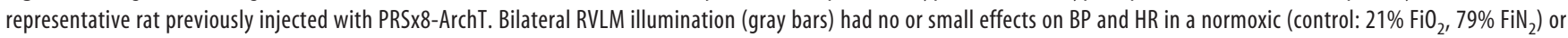
hypercapnic environment $\left(21 \% \mathrm{FiO}_{2}, 6 \% \mathrm{FiCO}_{2}, 73 \% \mathrm{FiN}_{2}\right)$, but produced a large hypotension and mild bradycardia in hypoxia $\left(12 \% \mathrm{FiO}_{2}, 88 \% \mathrm{FiN}_{2}\right)$. The light reduced $\mathrm{F}_{\mathrm{R}}$ and $\mathrm{V}_{\mathrm{T}}$ during hypercapnia and normoxia, but had little effect on these parameters during hypoxia, as described previously for this viral vector injected in a similar location (Basting et al., 2015). $\boldsymbol{B}$, MAP at rest (closed circles) and at the end of a 10 s illumination of the RVLM (open circles) in a cohort of seven rats exposed to various inhaled gas mixtures. $(-\boldsymbol{E}$, Corresponding values of HR, $F_{R^{\prime}}$ and $V_{\mathrm{T}}$. Note, $\mathrm{FiO}_{2}$ level $21 \%$ and $\mathrm{FiCO}_{2} 0 \%$ represent the same data points. ${ }^{*} p<0.05$, ${ }^{* *} p<0.01$, ${ }^{* * *} p<0.001$, and ${ }^{* * * *} p<0.0001$. 

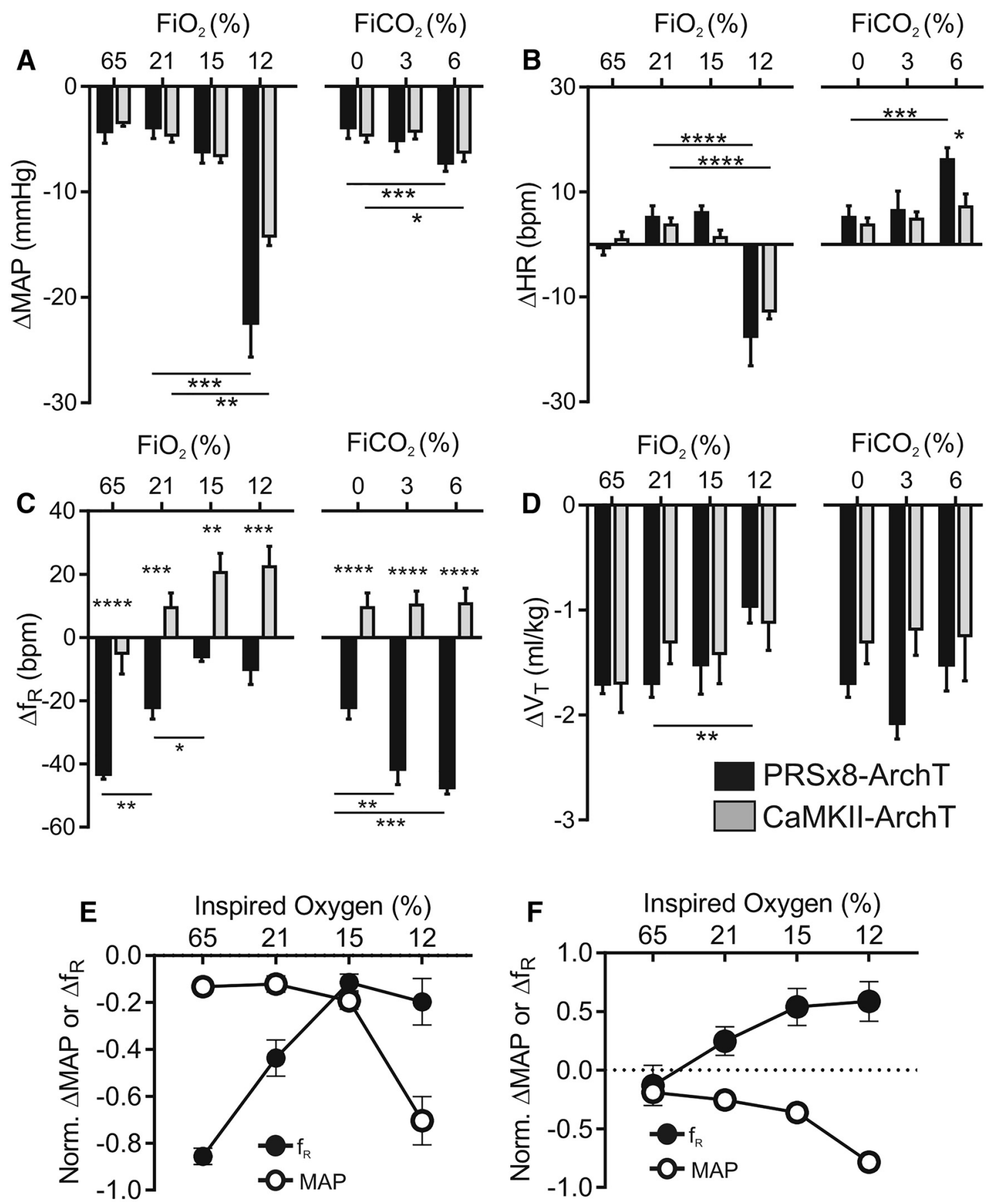

Figure 9. Comparison of cardiorespiratory changes induced by light in rats injected with CaMKII-ArchT versus PRSx8-ArchT. $A-D$, Average $(n=7$ for PRSx8-ArchT and $n=8$ for CaMKII-ArchT) effects of photoactivation on $\mathrm{MAP}(\boldsymbol{A}), \mathrm{HR}(\boldsymbol{B}), F_{\mathrm{R}}(\boldsymbol{(})$, and $V_{\mathrm{T}}(\boldsymbol{D})$ in rats injected with PRSx8-ArchT (black bars) and CaMKII-ArchT (gray bars) under varying $\mathrm{FiO}_{2}$ and $\mathrm{FiCO}_{2}$ levels. Note, $\mathrm{FiO}_{2}$ level $21 \%$ and $\mathrm{FiC}_{2} 0 \%$ represent the same data points. $E, F$, Plot of normalized changes in respiratory frequency ( $F_{\mathrm{R}}$, filled circles) and normalized changes in MAP (open circles) elicited by ArchT activation in rats injected with PRSx8-ArchT $(E, n=7)$ or CaMKII-ArchT $(F, n=8)$. Note that, in the PRSx8-ArchT cohort, the hypotension was associated with a drop in $F_{R}$, whereas, in the CaMKII-ArchT rats, the hypotension was associated with an increase in $F_{\mathrm{R}}{ }^{*} p<0.05$, ${ }^{* *} p<0.01$, ${ }^{* * *} p<0.001$, and ${ }^{* * *} p<0.0001$.

also eventually returned to normal, albeit later than MAP (Fig. 11C). Sham surgery had no effect on resting MAP or HR at any time point (two-way repeated-measures ANOVA; main effect of time on $\operatorname{MAP} F_{(7,16)}=0.8419, p=0.5693$; main effect of time on $\operatorname{HR} F_{(7,16)}=0.2505, p=0.9646$; Fig. $\left.11 D, E\right)$. BP variability was greatly enhanced in the $3 \mathrm{~d}$ after SAD compared with sham $(p<$ 0.05 ; Sidak's multiple-comparisons test after significant two-way repeated-measures ANOVA; $\left.F_{(7,28)}=48.46, p=0.0011\right)$ and returned toward control after $20 \mathrm{~d}$ (Fig. 12C,E). Sham surgery had no effect on BP variability at any time point (Fig. 12C,E). These results confirm prior observations in rats and other species (Norman et al., 1981; Osborn and England, 1990).

Before surgery, ArchT photoinhibition only produced a small BP drop $(-4.2 \pm 0.5$ and $-5.3 \pm 2.3 \mathrm{mmHg}$ for SAD and sham groups, respectively; Fig. 12D). In contrast, the light-induced BP drop was profound $1-4 \mathrm{~d}$ after SAD (up to $-35.0 \pm 5.1 \mathrm{mmHg}$; Figs. $11 B, 12 D)$ and much greater than after sham operation $(p<$ 0.0001; Sidak's multiple-comparisons test after significant two- 

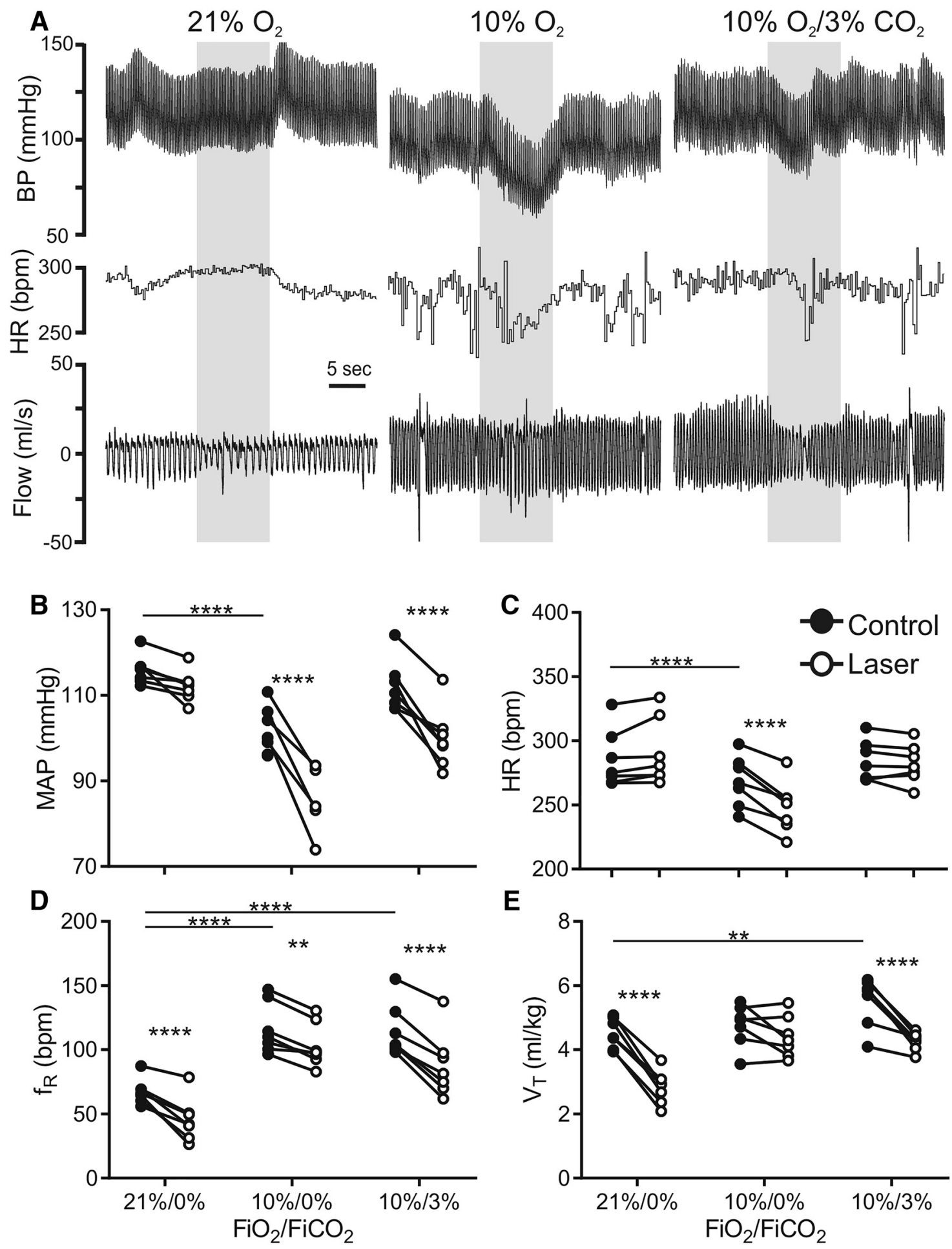

Figure 10. Addition of $\mathrm{CO}_{2}$ reverses the effects of hypoxia on cardiovascular variables. $A$, Representative recording of $\mathrm{BP}$, $\mathrm{HR}$, and respiratory flow (Flow) from a rat previously injected with PRSx8-ArchT. Bilateral photoinhibition of RVLM neurons (gray bars) had little effect on BP and $\mathrm{HR}$ in control conditions $\left(21 \% \mathrm{FiO}_{2}, 79 \% \mathrm{FiN}_{2}\right)$, but produced a large hypotension and bradycardia in hypoxia $\left(10 \% \mathrm{FiO}_{2}, 90 \% \mathrm{FiN}_{2}\right)$. Addition of $\mathrm{CO}_{2}$ to the hypoxic mixture $\left(10 \% \mathrm{FiO}_{2}, 3 \% \mathrm{FiCO}_{2}, 87 \% \mathrm{FiN}_{2}\right)$ reduced the hypotension and bradycardia and restored some breathing inhibition. $\boldsymbol{B}-\boldsymbol{E}$, Data for all experimental animals $(n=7)$ : $\operatorname{MAP}(\boldsymbol{B}), \operatorname{HR}(\boldsymbol{C}), F_{\mathrm{R}}(\boldsymbol{D})$, and $V_{\mathrm{T}}(\boldsymbol{E})$. Filled circles are resting values; open circles are values during bilateral inhibition with ArchT. ${ }^{*} p<0.05,{ }^{* *} p<0.01$, ${ }^{* * *} p<0.001$, and ${ }^{* * *} p<0.0001$.

way repeated-measures ANOVA; $\left.F_{(7,28)}=19.12, p<0.0001\right)$. In fact, $1 \mathrm{~d}$ after surgery, when resting $\mathrm{BP}$ was at its peak, ArchT photoactivation reduced $\mathrm{BP}$ to levels equivalent to those before SAD (Fig. 11B). On days 2-4 after SAD, although MAP returned to control levels, RVLM photoinhibition continued to produce $\mathrm{BP}$ drops of $>30 \mathrm{mmHg}$, a hypotension relative to presurgery
MAP levels (Figs. 11B, 12D). By comparison, the effects of ArchT photoactivation on HR were minor. On days 3 and 4 after SAD, the light caused a statistically significant decrease in $\operatorname{HR}(-20.3 \pm$ 3.2 and $-11.2 \pm 4.2 \mathrm{bpm}$, respectively; $p<0.01$; Sidak's multiple-comparisons test after significant two-way repeatedmeasures ANOVA; $\left.F_{(7,28)}=5.088, p<0.0008\right)$. However, these 


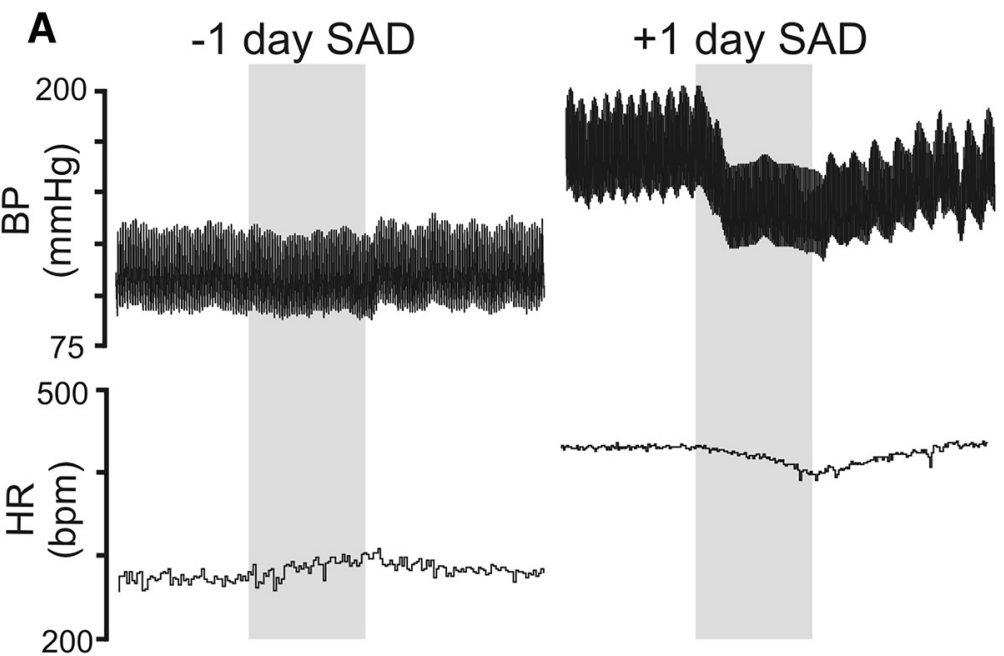

B

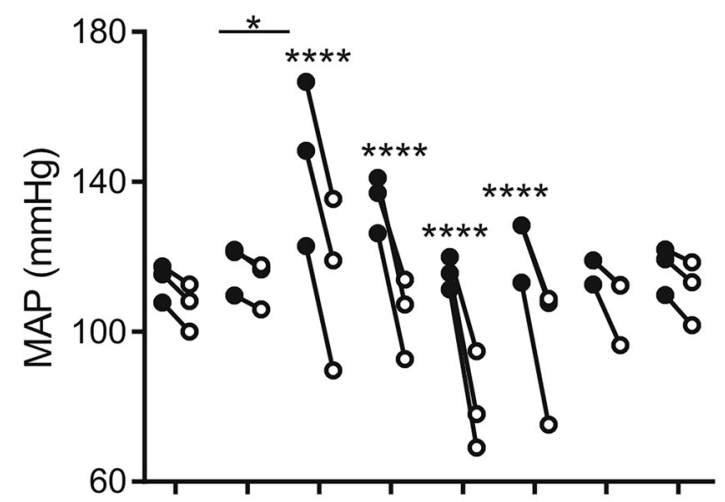

SAD

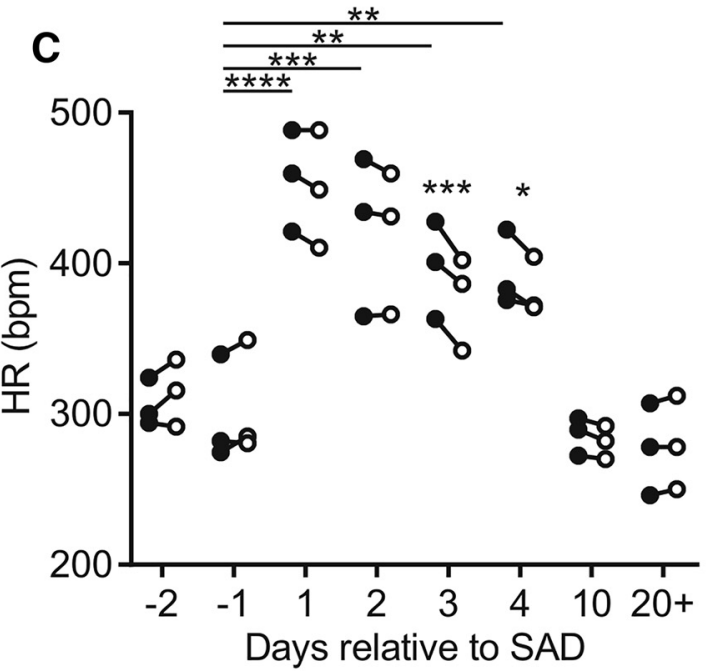

D

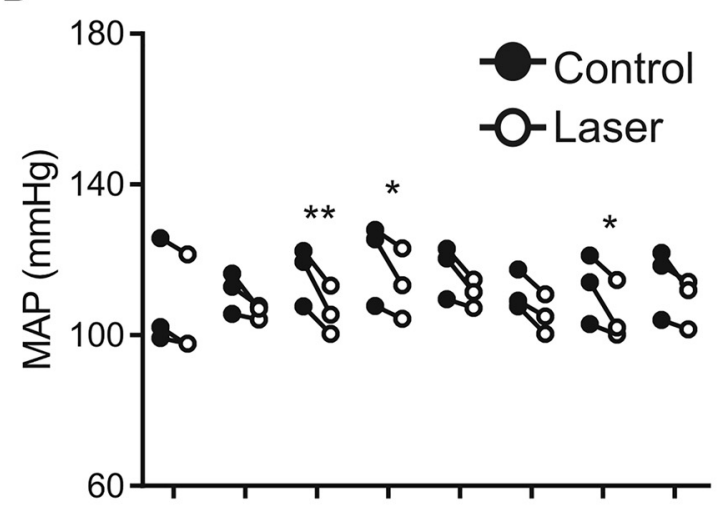

E

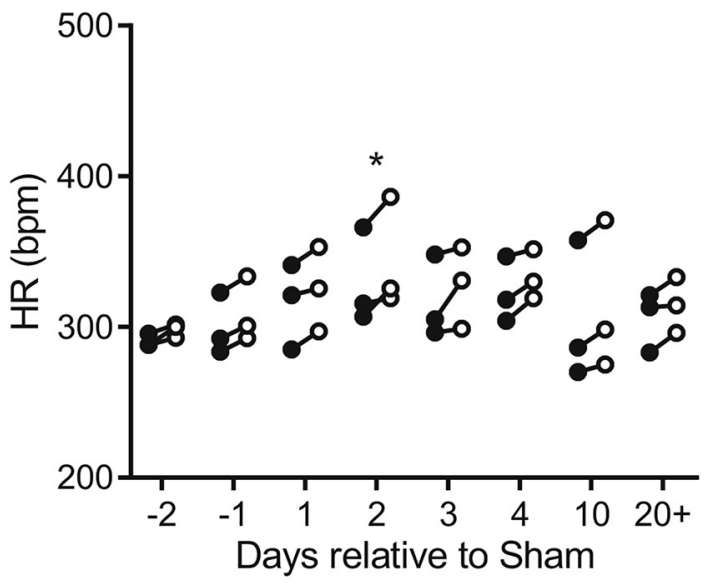

Figure 11. Time-dependent contribution of $C 1$ neurons to BP after SAD. A, effect of bilateral RVLM illumination on BP and HR $24 \mathrm{~h}$ before $(-1 \mathrm{~d}), 1 \mathrm{~d}$ after, or $20 \mathrm{~d}$ after SAD in a resting unanesthetized rat previously injected with PRSx8-ArchT. The light had very little effect before and $20 \mathrm{~d}$ after SAD, but produced a large hypotension the day after this surgery. B, C, Group data for denervated rats $(n=3)$. MAP during $10 \mathrm{~s}$ preceding light delivery (closed circles) and during the last $2 \mathrm{~s}$ of the $10 \mathrm{~s} \mathrm{light}$ pulse (open circles). The values are the mean of at least five trials per time point for each rat. $\boldsymbol{C}$, HR recorded during the same period of time as in $\boldsymbol{B} . \boldsymbol{D}, \boldsymbol{E}$, MAP and HR in sham-operated rats $(n=3)$ subjected to the same protocol. ${ }^{*} p<0.05$, ${ }^{* *} p<0.01$, ${ }^{* * *} p<0.001$, and ${ }^{* * *} p<0.0001$.

decreases were quite small, particularly compared with the changes in HR evoked by SAD surgery (Fig. 11B).

Before their respective surgeries, the $\mathrm{SAD}$ and sham groups responded identically to ArchT photoinhibition, both in the conscious state and under isoflurane anesthesia $(p=0.95$ and 0.60 for control and isoflurane conditions respectively; Sidak multiple-comparisons test after two-way ANOVA; $F_{(1,4)}=0.6224, p=0.4743$; Fig. 12A). In addition, the number of ArchT-transduced neurons present in the 

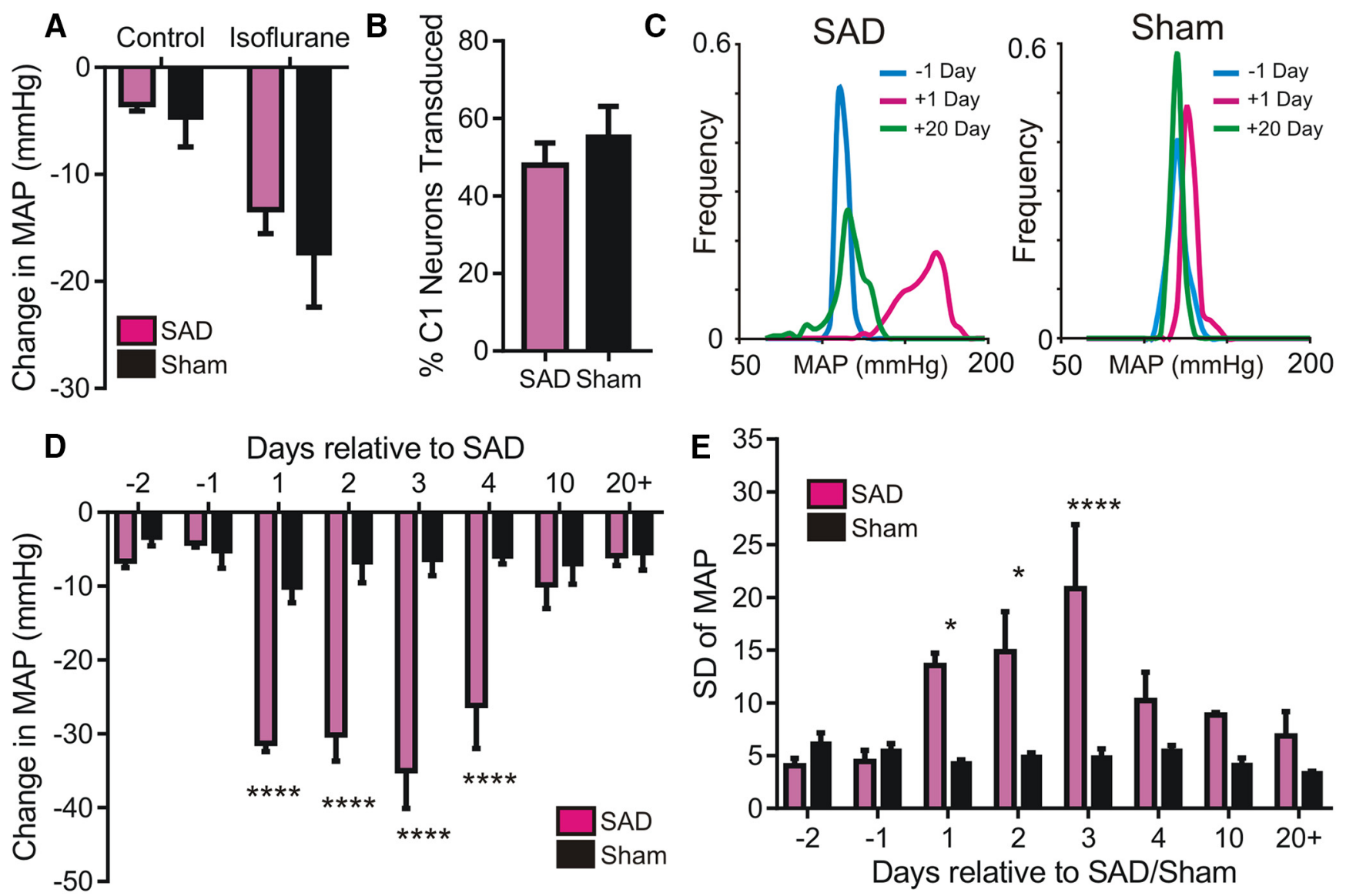

Figure 12. Hemodynamic changes elicited by RVLM inhibition in rats injected with PRSx8-ArchT vector: comparison between SADand sham-operated animals. $\boldsymbol{A}$, Before surgery, ArchT photoactivation produced the same degree of hypotension at rest or under isoflurane anesthesia in the $S A D$ cohort (magenta bars; $n=3$ ) and the sham-operated controls (black bars; $n=3$ ). $\boldsymbol{B}, S A D$ and sham-operated rats had the same number of ArchT-transduced C1 RVLM neurons. C, BP variability $1 \mathrm{~d}$ before (blue), $1 \mathrm{~d}$ after (magenta), and $20 \mathrm{~d}$ after surgery (green) in a representative SAD rat (left) and a sham-operated rat (right). D, Maximum hypotension elicited by $10 \mathrm{~s}$ ArchT photoactivation before and after surgery in SAD (magenta bars) and sham-operated rats (black bars; $n=3$ for each group). $\boldsymbol{E}$, BP variability (reported as SD) before and after SAD (magenta bars) or sham surgery (black bars). ${ }^{*} p<0.05,{ }^{* *} p<0.01,{ }^{* * *} p<0.001$, and ${ }^{* * * *} p<0.0001$.

RVLM was very similar in both groups ( $p=0.48$; unpaired $t$ test; Fig. $12 B)$. Therefore, the difference between SAD and sham rats could not be explained by a difference in the number of transduced $\mathrm{Cl}$ neurons or the placement of the optical fibers.

\section{sBRS during control, hypoxic and hypercapnic conditions}

To assess sBRS under normoxia, hypoxia and hypercapnia, we used the "sequence method," which is based on the detection and analysis of time periods during which SBP and PI covary, presumably reflecting baroreflex activity (Fig. 13A) (Bajić et al., 2010). To validate this method, we measured sBRS in three rats $24 \mathrm{~h}$ after SAD. The reflex was reduced by $\sim 60 \%$, whereas no difference was noted after sham surgery in three control rats $(p<$ 0.05; Sidak's multiple-comparisons test after significant two-way repeated-measures ANOVA; $F_{(1,4)}=19.12, p<0.0001$; Fig. $13 C$, top). Similar numbers of sequences were found before and after $\mathrm{SAD} /$ sham (two-way repeated-measures ANOVA; $F_{(1,4)}=$ $0.0001, p=0.9910$; Fig. $13 C$, bottom). In short, the sequence method seemed to provide a credible index of the cardiac baroreflex in these rats.

The comparison of sBRS was performed in 23 rats; this included the high- and low-responders from the PRSx8-ArchT and CaMKII-ArchT groups. Productive sequences were identified during normoxia, hypoxia $\left(12 \% \mathrm{FiO}_{2}\right)$, and hypercapnia $(6 \%$ $\mathrm{FiCO}_{2}$ ) (Fig. 13D). The analysis of these sequences revealed that the gain of the cardiac baroreflex $(1.1 \pm 0.1 \mathrm{~ms} / \mathrm{mmHg}$ in nor- moxia; Fig. 13E) was significantly elevated to $2.8 \pm 0.5 \mathrm{~ms} /$ $\mathrm{mmHg}$ during hypoxia and $1.5 \pm 0.1 \mathrm{~ms} / \mathrm{mmHg}$ during hypercapnia ( $p<0.001$ and $p<0.01$ for hypoxia and hypercapnia, respectively; Dunn's multiple-comparisons test after significant Friedman's test; $\mathrm{Q}=15.22, p=0.0005)$. The number of sequences identified per 1000 heartbeats was fairly consistent across the conditions, with a slight drop during hypoxia $(p<$ 0.05; Dunn's multiple-comparisons test after significant Friedman's test; $\mathrm{Q}=9.478, p=0.0087$; Fig. $13 F$ ). In addition, the sequences identified in hypoxia were a bit shorter, as indicated by a decrease in the number of beats $(p<0.0001$; Tukey's multiplecomparisons test after significant one-way repeated-measures ANOVA; $F=7.558, p=0.0025)$ and the change in SBP of the sequences $(p<0.05$; Tukey's multiple-comparisons test after significant one-way repeated-measures ANOVA; $F=33.11, p<$ 0.0001; Fig. 13G,H).

In sum, the baroreflex is actually potentiated rather than attenuated by hypoxia. The larger BP drop elicited by photoinhibiting RVLM neurons under hypoxia compared with normoxia cannot be explained by a reduction in the baroreflex.

\section{Discussion}

We show here that $\mathrm{C} 1$ neuron activation prevents $\mathrm{BP}$ from falling in hypoxic unanesthetized rats. In contrast, we find that changes in breathing have little effect on the ability of $\mathrm{C} 1$ neurons to regulate $\mathrm{BP}$. We also demonstrate that the contribution of $\mathrm{C} 1$ to 

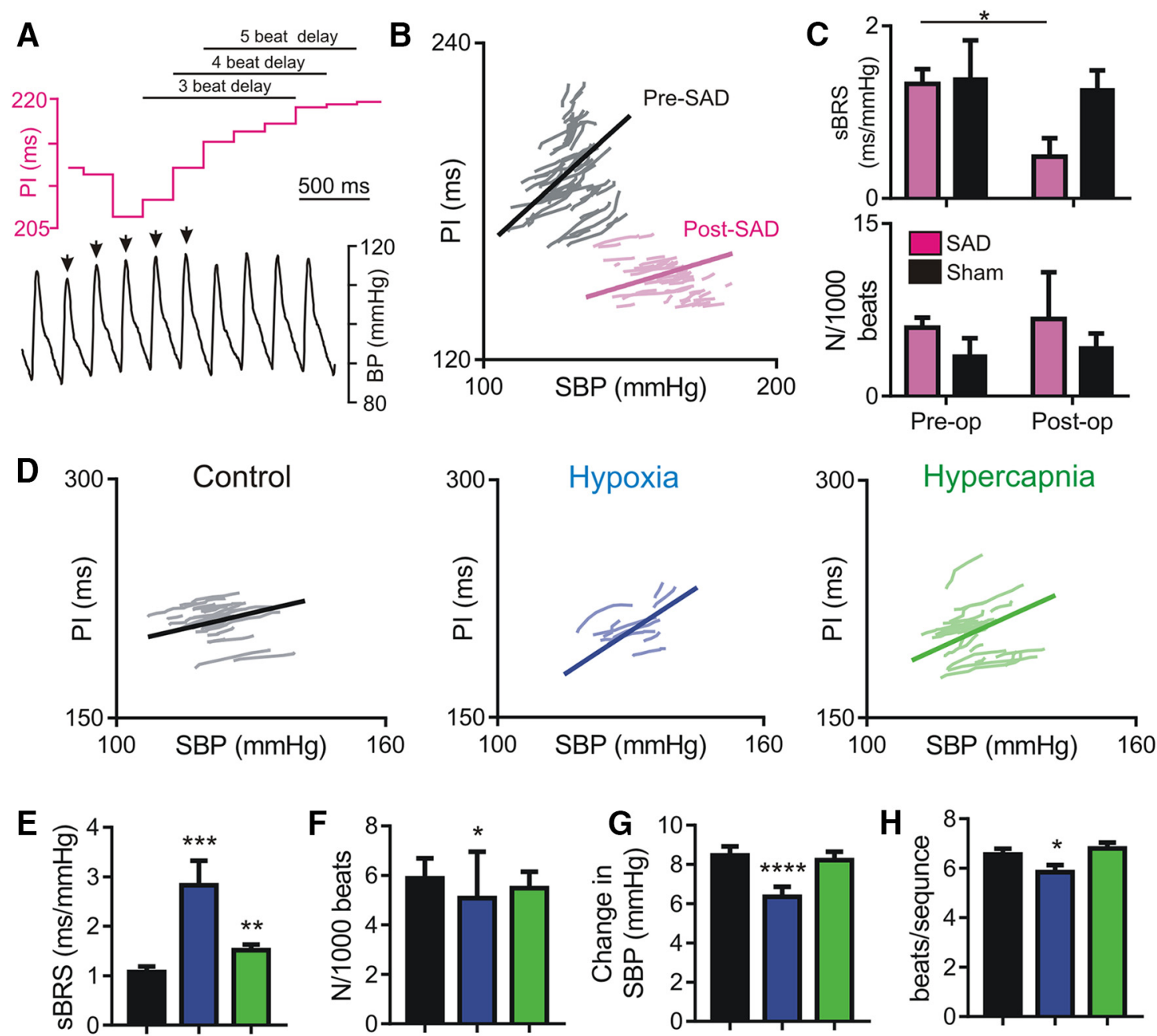

Figure 13. $s B R S$ is increased by hypoxia and, to a lesser degree, by hypercapnia. $A$, Example of one baroreflex "sequence" selected in a conscious rat. Arrows indicate BP pulses that were selected for measurement of SBRS (five contiguous pulses during which systolic BP and SBP increased and PI also increased at the indicated delays). $B$, sequences collected before (pre-SAD; black) and after (post-SAD, magenta) $S A D$ in a representative animal. The slope of the average regression line is greatly reduced after $S A D$ denoting baroreflex impairment. $C$, Mean sBRS was significantly reduced after $\operatorname{SAD}$ surgery $(n=3$, magenta bars), but unchanged after sham operation ( $n=3$, black bars). The number of sequences per 1000 heart beats ( $n / 1000$ beats) was not significantly different between the groups. $D$, Sequences observed under normoxia at rest (control, black), hypoxia (blue), and hypercapnia (green) in one rat. The sBRS value for each animal in each condition is the slope of the regression line (thick darker lines). In this example, there are fewer sequences for hypoxia $(n=9)$ than control $(n=22)$ or hypercapnia $(n=27)$; however, this is mostly due to a shorter exposure time to hypoxia. The number of sequences per 1000 heart beats is similar between these conditions for this rat $(4.8,3.1$, and 6.8 for control, hypoxia, and hypercapnia, respectively). $\boldsymbol{E}-\boldsymbol{H}$, Average $(n=23)$ sBRS $(\boldsymbol{E})$ as determined by the "sequence" method during control $\left(21 \% \mathrm{FiO}_{2}\right)$, hypoxic $\left(12 \% \mathrm{FiO}_{2}\right)$, and hypercapnic $\left(6 \% \mathrm{FiCO}_{2}\right)$ conditions. $\boldsymbol{E}$, sBRS was increased during hypoxia and hypercapnia $(n=23)$. In hypoxia, there were small, significant reductions in the number of sequences observed $(n / 1000$ beats, $\boldsymbol{F})$, the change in SBP over a sequence (change in SBP, $\boldsymbol{G}$ ), and the number of beats in observed sequences (beats per sequence, $\boldsymbol{H}) .{ }^{*} p<0.05,{ }^{* *} p<0.01,{ }^{* * *} p<0.001$, and ${ }^{* * *} p<0.0001$.

$\mathrm{BP}$ is enhanced under isoflurane anesthesia or in SAD conscious rats. We conclude that baroreceptors and peripheral chemoreceptors are the main regulators of $\mathrm{C} 1$ activity and $\mathrm{BP}$ in conscious resting rats and that these sensory afferents regulate $\mathrm{C} 1$ cell activity largely independently of changes in respiration.

\section{Minor contribution of $\mathrm{C} 1$ neurons to $\mathrm{BP}$ at rest in normoxia}

$\mathrm{C} 1$ neuron inhibition produced very small BP drops in quietly resting rats breathing room air, suggesting that, unlike in anesthetized or reduced rodent preparations (Marina et al., 2011), C1 neuron activity is low. Consistent with this interpretation, $\mathrm{C} 1$ lesions produce very small BP reductions in awake rats (Madden et al., 2006). Both approaches have certain limitations. In our case, we estimate that at most $53 \pm 4 \%$ of the relevant (bulbospinal) C1 neurons expressed ArchT; the other barosensitive neurons ( $\mathrm{C} 1$ or others) could have attenuated the BP changes elicited by inhibiting the transduced population. Likewise, plas- ticity changes or alternative circuits may compensate even after large destruction of C1 neurons (Madden et al., 2006).

\section{Postinhibitory rebound}

SNA and BP briefly rebounded after the light pulses. This phenomenon was probably caused by transient synchronous reactivation of ArchT-transduced C1 neurons. This rebound is likely a cell-autonomous consequence of ArchT activation rather than a network-related effect because it was observed only in cells that were silenced by the light. This rebound may be caused by h-current, which is prominent in C1 (Li et al., 1995).

\section{Effect of isoflurane anesthesia}

ArchT-mediated C1 inhibition produced much larger BP drops in isoflurane-anesthetized than unanesthetized rats. Either isoflurane inhibits a compensatory mechanism that normally limits $\mathrm{C} 1$ neuron influence on $\mathrm{BP}$ or these neurons are activated during 
isoflurane. Indeed, RVLM-barosensitive neurons are far more active (up to $35 \mathrm{~Hz}$ ) in rats anesthetized with halogenated anesthetics than with most other agents except chloralose (Abbott et al., 2009a). Baroreflex impairment likely contributes to the excitatory effect of isoflurane on $\mathrm{Cl}$, but cell-autonomous effects of this anesthetic on leak potassium and other channels may also contribute (Lazarenko et al., 2010).

\section{Arterial baroreceptor denervation}

SAD produces a severe but short-lasting hypertension that is largely mediated by increased SNA and reduced cardiovagal tone (Norman et al., 1981; Irigoyen et al., 1995). C1 neuron photoinhibition reduced BP far more after SAD than before, suggesting that these neurons had been activated and were at least partly responsible for the hypertension. This result conforms to expectations because arterial baroreceptors are active at rest and inhibit C1 neurons via two interneurons (Schreihofer and Guyenet, 1997; Chan and Sawchenko, 1998; Dampney et al., 2003; Guyenet, 2006).

Consistent with prior studies, we found that resting BP returns to normal within $3 \mathrm{~d}$ after SAD (Norman et al., 1981; Osborn and England, 1990). Osborn and England (1990) found no net change in sodium excretion after SAD in rats and thus suggested that the rapid normalization of $\mathrm{BP}$ results from an equally fast return of SNA to control (pre-SAD) levels. We were therefore expecting that the $\mathrm{BP}$ drop elicited by $\mathrm{C} 1$ neuron inhibition would decrease in parallel with the hypertension. However, C1 photoinhibition still elicited large BP drops $2 \mathrm{~d}$ after resting $\mathrm{BP}$ had returned to control. At least three potential explanations come to mind. SNA may actually be normal during this transition period (3-5 d after SAD), but the specific contribution of the C1 neurons to this outflow could be greater than normal. The heart or blood vessels may be desensitized to catecholamines for up to $5 \mathrm{~d}$ after SAD, causing BP to return to the control level earlier than SNA. Some unknown humoral factor may attenuate the stimulatory effect of SNA on the cardiovascular system.

After $10 \mathrm{~d}$, all observable effects of SAD had disappeared except an increase in BP variability; BP and HR were both normal and RVLM inhibition produced the same small effects at rest as before SAD. Potential reasons for this recovery include regrowth of arterial baroreceptor afferents (Cai et al., 2003), reduced C1 activity via homeostatic plasticity, or a network-level adaptation (Osborn et al., 2005).

\section{Hypoxia and hypercapnia}

In PRSX8-ArchT-treated rats, RVLM photoinhibition elicited larger BP reductions under hypoxia than normoxia and the hypotension was approximately proportional to the number of transduced $\mathrm{C} 1$ cells. Therefore, under hypoxia, $\mathrm{C} 1$ activation prevents $\mathrm{BP}$ from falling. $\mathrm{C} 1$ activation presumably originates from carotid body afferents, which provide powerful and possibly direct (single interneuron) excitatory input to $\mathrm{C} 1$ (Sun and Reis, 1994; Aicher et al., 1996; Guyenet, 2014). C1 neurons may also respond to hypoxia in a cell-autonomous manner or via astrocytes (Reis et al., 1994; Angelova et al., 2015). C1 activation by hypoxia may also have been potentiated by the baroreflex because hypoxia reduced baseline BP slightly and sensitized this reflex (see present data for the cardiovagal reflex and Malpas et al., 1996, for the sympathetic component).

The breathing changes elicited in the PRSx8-ArchT cohort were presumably caused by inhibition of RTN neurons, which are also transduced after injection of PRSx8-ArchT into RVLM (Basting et al., 2015). However, RTN inhibition cannot explain the hypotension observed during hypoxia. These neurons are $\mathrm{CO}_{2}$ activated and stimulate breathing but become silent under hypoxia because of the ensuing respiratory alkalosis (Basting et al., 2015). Therefore, under hypoxia, further hyperpolarization of ArchT-transduced RTN neurons should have no effect on any physiological variable, BP included.

In anesthetized preparations, $\mathrm{C} 1$ neurons are moderately activated by hypercapnia (Guyenet et al., 2005; Moreira et al., 2006) and their discharge pattern, like that of SNA, is respiratory modulated (Haselton and Guyenet, 1989a; Moraes et al., 2013; Guyenet, 2014). Central cardiorespiratory coupling (the phasic modulation of sympathetic efferents by the respiratory pattern generator) is therefore viewed as a potentially important regulator of sympathetic tone and BP (Simms et al., 2009; Guyenet, 2014; Moraes et al., 2014). In the present study, the BP drop elicited by RVLM photoinhibition was only marginally larger in rats breathing $6 \% \mathrm{FiCO}_{2}$ than room air. One explanation could be that cardiorespiratory coupling is mediated predominantly through neurons other than C1. However, this interpretation is unsatisfactory because RVLM photoinhibition greatly reduced $F_{\mathrm{R}}$ and amplitude. This effect, presumably caused by RTN neuron inhibition (Basting et al., 2015), should have reduced cardiorespiratory coupling wherever it might occur and should have caused a large BP drop if cardiorespiratory coupling were important to sustain BP. This was not observed, so our results suggest that cardiorespiratory coupling contributes very little to $\mathrm{BP}$ in conscious rats breathing up to $6 \% \mathrm{FiCO}_{2}$. Central cardiorespiratory coupling may play a greater role at higher levels of hypercapnia, during exercise, or in pathological situations (hypertension, chronic intermittent hypoxia; Molkov et al., 2014; Moraes et al., 2014).

The most noticeable effect of moderate hypercapnia $(3 \%$ $\mathrm{FiCO}_{2}$ ) was a reduction of the $\mathrm{BP}$ drop elicited by $\mathrm{C} 1$ cell inhibition in hypoxic rats. This result indicates that $\mathrm{CO}_{2}$ had actually significantly reduced the activity of these neurons despite the further activation of the breathing network. The most likely explanation is that, by stimulating breathing, $\mathrm{CO}_{2}$ had reduced arterial hypoxemia and carotid body activation, thereby reducing the discharge rate of $\mathrm{C} 1$ (Basting et al., 2015).

\section{Cardiorespiratory effects elicited by inhibiting RVLM neurons transduced with CaMKII-ArchT}

We found the CaMKII-ArchT vector transduced glutamatergic and GABAergic neurons with little selectivity, unlike in the forebrain (Watakabe et al., 2015). As in PRSx8-ArchT-treated rats, photoinhibition of CaMKII-ArchT-transduced RVLM neurons produced larger BP drops under hypoxia than normoxia, but the associated breathing responses were very different. In CaMKII-ArchT-injected rats, ArchT activation increased $F_{\mathrm{R}}$, presumably by inhibiting Bötzinger neurons (Marchenko et al., 2016), whereas the breathing inhibition observed in PRSx8-ArchT-treated rats is caused by inhibition of RTN neurons (Basting et al., 2015).

Fewer $\mathrm{Cl}$ neurons were transduced in rats that received CaMKIIArchT instead of PRSx8-ArchT. However, when animals with similar numbers of transduced $\mathrm{C} 1$ cells were compared, RVLM illumination produced larger BP drops in the CaMKII-ArchT than in the PRSx8-ArchT cohort. Three explanations seem plausible. CaMKII-ArchT transduces a subset of $\mathrm{C} 1$ neurons with higher than average contributions to SNA, ArchT was expressed at higher levels in the transduced $\mathrm{C} 1$ neurons, or CaMKII-ArchT also transduced "non-C1" neurons that contribute to BP control, that is, non-C1 presympathetic neurons or excitatory interneurons that drive the sympathoexcitatory neurons. 


\section{Conclusions}

In conscious rats, $\mathrm{C} 1$ activation prevents $\mathrm{BP}$ from falling during hypoxia and contributes to the hypertension elicited by baroreceptor denervation. $\mathrm{Cl}$ cells are also activated by isoflurane, which minimizes the hypotension that would otherwise result from the depressant effects of the anesthetic on the circulatory system. These results highlight the importance of $\mathrm{C} 1$ to $\mathrm{BP}$ stability in conscious mammals. Central cardiorespiratory modulation of $\mathrm{C} 1$ neurons contributes very little to resting $\mathrm{BP}$ in conscious normotensive rats, but our findings are fully compatible with the notion that carotid body hyperactivity or brainstem hypoxia could produce hypertension by activating C1 (Geraldes et al., 2014; Marina et al., 2015; Pijacka et al., 2016).

\section{References}

Abbott SB, Stornetta RL, Socolovsky CS, West GH, Guyenet PG (2009a) Photostimulation of channelrhodopsin-2 expressing ventrolateral medullary neurons increases sympathetic nerve activity and blood pressure in rats. J Physiol 587:5613-5631. CrossRef Medline

Abbott SB, Stornetta RL, Fortuna MG, Depuy SD, West GH, Harris TE, Guyenet PG (2009b) Photostimulation of retrotrapezoid nucleus phox $2 \mathrm{~b}$-expressing neurons in vivo produces long-lasting activation of breathing in rats. J Neurosci 29:5806-5819. CrossRef Medline

Abbott SB, Kanbar R, Bochorishvili G, Coates MB, Stornetta RL, Guyenet PG (2012) C1 neurons excite locus coeruleus and A5 noradrenergic neurons along with sympathetic outflow in rats. J Physiol 590:28972915. CrossRef Medline

Abe C, Iwata C, Morita H (2013) Water drinking-related muscle contraction induces the pressor response via mechanoreceptors in conscious rats. J Appl Physiol 114:28-36. CrossRef Medline

Aicher SA, Saravay RH, Cravo S, Jeske I, Morrison SF, Reis DJ, Milner TA (1996) Monosynaptic projections from the nucleus tractus solitarii to C1 adrenergic neurons in the rostral ventrolateral medulla: comparison with input from the caudal ventrolateral medulla. J Comp Neurol 373:62-75. CrossRef Medline

Angelova PR, Kasymov V, Christie I, Sheikhbahaei S, Turovsky E, Marina N, Korsak A, Zwicker J, Teschemacher AG, Ackland GL, Funk GD, Kasparov S, Abramov AY, Gourine AV (2015) Functional oxygen sensitivity of astrocytes. J Neurosci 35:10460-10473. CrossRef Medline

Bajić D, Loncar-Turukalo T, Stojicić S, Sarenac O, Bojić T, Murphy D, Paton JF, Japundzić-Zigon N (2010) Temporal analysis of the spontaneous baroreceptor reflex during mild emotional stress in the rat. Stress 13:142154. CrossRef Medline

Basting TM, Burke PG, Kanbar R, Viar KE, Stornetta DS, Stornetta RL, Guyenet PG (2015) Hypoxia silences retrotrapezoid nucleus respiratory chemoreceptors via alkalosis. J Neurosci 35:527-543. CrossRef Medline

Brown DL, Guyenet PG (1985) Electrophysiological study of cardiovascular neurons in the rostral ventrolateral medulla in rats. Circ Res 56:359-369. CrossRef Medline

Burke PG, Abbott SB, Coates MB, Viar KE, Stornetta RL, Guyenet PG (2014) Optogenetic stimulation of adrenergic C1 neurons causes sleep statedependent cardiorespiratory stimulation and arousal with sighs in rats. Am J Respir Crit Care Med 190:1301-1310. CrossRef Medline

Burke PG, Kanbar R, Basting TM, Hodges WM, Viar KE, Stornetta RL, Guyenet PG (2015) State-dependent control of breathing by the retrotrapezoid nucleus. J Physiol 593:2909-2926. CrossRef Medline

Cai GJ, Li L, Xie HH, Xu JJ, Miao CY, Su DF (2003) Morphological evidence of reinnervation of the baroreceptive regions in sinoaortic-denervated rats. Clin Exp Pharmacol Physiol 30:925-929. CrossRef Medline

Chan RK, Sawchenko PE (1998) Organization and transmitter specificity of medullary neurons activated by sustained hypertension: implications for understanding baroreceptor reflex circuitry. J Neurosci 18:371-387. Medline

Chow BY, Han X, Dobry AS, Qian X, Chuong AS, Li M, Henninger MA, Belfort GM, Lin Y, Monahan PE, Boyden ES (2010) High-performance genetically targetable optical neural silencing by light-driven proton pumps. Nature 463:98-102. CrossRef Medline

Dampney RA, Horiuchi J, Tagawa T, Fontes MA, Potts PD, Polson JW (2003) Medullary and supramedullary mechanisms regulating sympathetic vasomotor tone. Acta Physiol Scand 177:209-218. CrossRef Medline
Geraldes V, Goncalves-Rosa N, Liu B, Paton JF, Rocha I (2014) Essential role of RVL medullary neuronal activity in the long term maintenance of hypertension in conscious SHR. Auton Neurosci 186:22-31. CrossRef Medline

Guyenet PG (2006) The sympathetic control of blood pressure. Nat Rev Neurosci 7:335-346. Medline

Guyenet PG (2014) Regulation of breathing and autonomic outflows by chemoreceptors. Compr Physiol 4:1511-1562. CrossRef Medline

Guyenet PG, Mulkey DK, Stornetta RL, Bayliss DA (2005) Regulation of ventral surface chemoreceptors by the central respiratory pattern generator. J Neurosci 25:8938-8947. CrossRef Medline

Han X, Chow BY, Zhou H, Klapoetke NC, Chuong A, Rajimehr R, Yang A, Baratta MV, Winkle J, Desimone R, Boyden ES (2011) A high-light sensitivity optical neural silencer: development and application to optogenetic control of non-human primate cortex. Front Syst Neurosci 5:18. CrossRef Medline

Haselton JR, Guyenet PG (1989a) Central respiratory modulation of medullary sympathoexcitatory neurons in rat. Am J Physiol 256:R739-R750. Medline

Haselton JR, Guyenet PG (1989b) Electrophysiological characterization of putative $\mathrm{C} 1$ adrenergic neurons in the rat. Neurosci 30:199-214. CrossRef Medline

Hwang DY, Carlezon WA Jr, Isacson O, Kim KS (2001) A high-efficiency synthetic promoter that drives transgene expression selectively in noradrenergic neurons. Hum Gene Ther 12:1731-1740. CrossRef Medline

Irigoyen MC, Moreira ED, Ida F, Pires M, Cestari IA, Krieger EM (1995) Changes of renal sympathetic activity in acute and chronic conscious sinoaortic denervated rats. Hypertension 26:1111-1116. CrossRef Medline

Jansen AS, Wessendorf MW, Loewy AD (1995a) Transneuronal labeling of CNS neuropeptide and monoamine neurons after pseudorabies virus injections into the stellate ganglion. Brain Res 683:1-24. CrossRef Medline

Jansen AS, Nguyen XV, Karpitskiy V, Mettenleiter TC, Loewy AD (1995b) Central command neurons of the sympathetic nervous system:basis of the fight-or flight response. Science 270:644-646. CrossRef Medline

Kanbar R, Stornetta RL, Cash DR, Lewis SJ, Guyenet PG (2010) Photostimulation of Phox $2 \mathrm{~b}$ medullary neurons activates cardiorespiratory function in conscious rats. Am J Respir Crit Care Med 182:1184-1194. CrossRef Medline

Krieger EM (1964) Neurogenic hypertension in the rat. Circ Res 15:511521. CrossRef Medline

Krupp J, Bordey A, Feltz P (1997) Electrophysiological evidence for multiple glycinergic inputs to neonatal rat sympathetic preganglionic neurons in vitro. Eur J Neurosci 9:1711-1719. CrossRef Medline

Lazarenko RM, Fortuna MG, Shi Y, Mulkey DK, Takakura AC, Moreira TS, Guyenet PG, Bayliss DA (2010) Anesthetic activation of central respiratory chemoreceptor neurons involves inhibition of a THIK-1-like background $\mathrm{K}(+)$ current. J Neurosci 30:9324-9334. CrossRef Medline

Li A, Nattie E (2006) Catecholamine neurones in rats modulate sleep, breathing, central chemoreception and breathing variability. J Physiol 570:385-396. CrossRef Medline

Li YW, Bayliss DA, Guyenet PG (1995) C1 neurons of neonatal rats: intrinsic beating properties and alpha 2-adrenergic receptors. Am J Physiol 269:R1356-R1369. Medline

Lin LH, Moore SA, Jones SY, McGlashon J, Talman WT (2013) Astrocytes in the rat nucleus tractus solitarii are critical for cardiovascular reflex control. J Neurosci 33:18608-18617. CrossRef Medline

Madden CJ, Stocker SD, Sved AF (2006) Attenuation of homeostatic responses to hypotension and glucoprivation after destruction of catecholaminergic rostral ventrolateral medulla (RVLM) neurons. Am J Physiol Regul Integr Comp Physiol 291:R751-R759. Medline

Malpas SC, Shweta A, Anderson WP, Head GA (1996) Functional response to graded increases in renal nerve activity during hypoxia in conscious rabbits. Am J Physiol 271:R1489-R1499. Medline

Marchenko V, Koizumi H, Mosher B, Koshiya N, Tariq MF, Bezdudnaya TG, Zhang R, Molkov YI, Rybak IA, Smith JC (2016) Perturbations of respiratory rhythm and pattern by disrupting synaptic inhibition within pre-Botzinger and Botzinger complexes. eNeuro 3: pii: ENEURO.001116.2016. CrossRef Medline

Marina N, Abdala AP, Korsak A, Simms AE, Allen AM, Paton JF, Gourine AV (2011) Control of sympathetic vasomotor tone by catecholaminergic $\mathrm{C} 1$ neurones of the rostral ventrolateral medulla oblongata. Cardiovasc Res 91:703-710. CrossRef Medline 
Marina N, Ang R, Machhada A, Kasymov V, Karagiannis A, Hosford PS, Mosienko V, Teschemacher AG, Vihko P, Paton JF, Kasparov S, Gourine AV (2015) Brainstem hypoxia contributes to the development of hypertension in the spontaneously hypertensive rat. Hypertension 65:775-783. CrossRef Medline

Mattis J, Tye KM, Ferenczi EA, Ramakrishnan C, O’Shea DJ, Prakash R, Gunaydin LA, Hyun M, Fenno LE, Gradinaru V, Yizhar O, Deisseroth K (2011) Principles for applying optogenetic tools derived from direct comparative analysis of microbial opsins. Nat Methods 9:159-172. CrossRef Medline

McAllen RM, May CN, Shafton AD (1995) Functional anatomy of sympathetic premotor cell groups in the medulla. Clin Exp Hypertens 17:209221. CrossRef Medline

Molkov YI, Zoccal DB, Baekey DM, Abdala AP, Machado BH, Dick TE, Paton JF, Rybak IA (2014) Physiological and pathophysiological interactions between the respiratory central pattern generator and the sympathetic nervous system. Prog Brain Res 212:1-23. CrossRef Medline

Moraes DJ, da Silva MP, Bonagamba LG, Mecawi AS, Zoccal DB, AntunesRodrigues J, Varanda WA, Machado BH (2013) Electrophysiological properties of rostral ventrolateral medulla presympathetic neurons modulated by the respiratory network in rats. J Neurosci 33:19223-19237. CrossRef Medline

Moraes DJ, Machado BH, Paton JF (2014) Specific respiratory neuron types have increased excitability that drive presympathetic neurones in neurogenic hypertension. Hypertension 63:1309-1318. CrossRef Medline

Moreira TS, Takakura AC, Colombari E, Guyenet PG (2006) Central chemoreceptors and sympathetic vasomotor outflow. J Physiol 577:369386. CrossRef Medline

Norman RA Jr, Coleman TG, Dent AC (1981) Continuous monitoring of arterial pressure indicates sinoaortic denervated rats are not hypertensive. Hypertension 3:119-125. CrossRef Medline

Oosting J, Struijker-Boudier HA, Janssen BJ (1997) Validation of a continuous baroreceptor reflex sensitivity index calculated from spontaneous fluctuations of blood pressure and pulse interval in rats. J Hypertens 15:391-399. CrossRef Medline

Osborn JW, England SK (1990) Normalization of arterial pressure after barodenervation-role of pressure natriuresis. Am J Physiol 259:R1172R1180. Medline

Osborn JW, Jacob F, Guzman P (2005) A neural set point for the long-term control of arterial pressure: beyond the arterial baroreceptor reflex. Am J Physiol Regul Integr Comp Physiol 288:R846-R855. Medline

Pijacka W, McBryde FD, Marvar PJ, Lincevicius GS, Abdala AP, Woodward L, Li D, Paterson DJ, Paton JF (2016) Carotid sinus denervation ameliorates renovascular hypertension in adult Wistar rats. J Physiol 594:62556266. CrossRef Medline

Reis DJ, Golanov EV, Ruggiero DA, Sun MK (1994) Sympatho-excitatory neurons of the rostral ventrolateral medulla are oxygen sensors and essential elements in the tonic and reflex control of the systemic and cerebral circulations. J Hypertens Suppl 12:S159-S180. Medline
Ross CA, Ruggiero DA, Park DH, Joh TH, Sved AF, Fernandez-Pardal J, Saavedra JM, Reis DJ (1984) Tonic vasomotor control by the rostral ventrolateral medulla: effect of electrical or chemical stimulation of the area containing $\mathrm{C} 1$ adrenaline neurons on arterial pressure, heart rate, and plasma catecholamines and vasopressin. J Neurosci 4:474-494. Medline

Rostig S, Kantelhardt JW, Penzel T, Cassel W, Peter JH, Vogelmeier C, Becker HF, Jerrentrup A (2005) Nonrandom variability of respiration during sleep in healthy humans. Sleep 28:411-417. Medline

Saeki Y, Hasegawa Y, Shibamoto T, Yamaguchi Y, Hayashi T, Tanaka S, Wang HG, Koyama S (1996) The effects of sevoflurane, enflurane, and isoflurane on baroreceptor-sympathetic reflex in rabbits. Anesth Analg 82: 342-348. Medline

Schreihofer AM, Guyenet PG (1997) Identification of C1 presympathetic neurons in rat rostral ventrolateral medulla by juxtacellular labeling in vivo. J Comp Neurol 387:524-536. CrossRef Medline

Schreihofer AM, Guyenet PG (2003) Baro-activated neurons with pulsemodulated activity in the rat caudal ventrolateral medulla express GAD67 mRNA. J Neurophysiol 89:1265-1277. Medline

Schreihofer AM, Sved AF (2011) The ventrolateral medulla and sympathetic regulation of arterial pressure. In: Central regulation of autonomic functions (Llewellyn-Smith IJ, Verberne AJ, eds), pp 78-97. New York: OUP.

Schreihofer AM, Stornetta RL, Guyenet PG (2000) Regulation of sympathetic tone and arterial pressure by rostral ventrolateral medulla after depletion of $\mathrm{C} 1$ cells in rat. J Physiol 221-236.

Simms AE, Paton JF, Pickering AE, Allen AM (2009) Amplified respiratorysympathetic coupling in the spontaneously hypertensive rat: does it contribute to hypertension? J Physiol 587:597-610. CrossRef Medline

Smith JC, Abdala AP, Koizumi H, Rybak IA, Paton JF (2007) Spatial and functional architecture of the mammalian brain stem respiratory network: a hierarchy of three oscillatory mechanisms. J Neurophysiol 98: 3370-3387. CrossRef Medline

Stornetta RL (2009) Neurochemistry of bulbospinal presympathetic neurons of the medulla oblongata. J Chem Neuroanat 38:222-230. CrossRef Medline

Sun MK, Reis DJ (1993) Differential responses of barosensitive neurons of rostral ventrolateral medulla to hypoxia in rats. Brain Res 609:333-337. CrossRef Medline

Sun MK, Reis DJ (1994) Hypoxia selectively excites vasomotor neurons of rostral ventrolateral medulla in rats. Am J Physiol 266:R245-R256. Medline

Umehara S, Tanaka M, Nishikawa T (2006) Effects of sevoflurane anesthesia on carotid-cardiac baroreflex responses in humans. Anesth Analg 102: 38-44. CrossRef Medline

Watakabe A, Ohtsuka M, Kinoshita M, Takaji M, Isa K, Mizukami H, Ozawa $\mathrm{K}$, Isa T, Yamamori T (2015) Comparative analyses of adeno-associated viral vector serotypes 1, 2, 5, 8 and 9 in marmoset, mouse and macaque cerebral cortex. Neurosci Res 93:144-157. CrossRef Medline 